Original Research Paper

\title{
Nursing Leadership Challenges and Opportunities During COVID-19 (SARS-CoV-2) Pandemic Response in Zambia
}

\author{
${ }^{1}$ Annette Mwansa Nkowane, ${ }^{2}$ Lonia Mwape, ${ }^{3}$ Peggy S. Chibuye and ${ }^{4}$ Clara Tembo \\ ${ }^{1,3}$ Independent Consultant, Nursing and Midwifery, Lusaka, Zambia \\ ${ }^{2}$ School of Nursing, Levy Mwanawasa Medical University, Zambia \\ ${ }^{4}$ Directorate of Nursing, Ministry of Health, Zambia
}

\author{
Article history \\ Received: 22-08-2021 \\ Revised: 16-10-2021 \\ Accepted: 21-10-2021 \\ Corresponding Author: \\ Annette Mwansa Nkowane \\ Independent Consultant, \\ Nursing and Midwifery, \\ Lusaka, Zambia \\ Email: annemwansa@gmail.com
}

\begin{abstract}
A nurse leader has the capacity to influence, coordinate and integrate nursing care for patients and families and advocate for the nursing profession to achieve positive health outcomes. In Zambia, nurse leaders operate at all levels of the health system and can contribute significantly to alleviating the negative outcomes of diseases of epidemic potential. The COVID-19 pandemic has provided an opportunity to strengthen nursing leadership efforts towards the reduction of morbidity and mortality from this outbreak. A cross-sectional survey of nurse leaders in six provinces of Zambia was conducted. The data was collected through telephone interviews and self-administered questionnaires on roles and responsibilities, nursing leadership, involvement in policy advice and overall experience with the COVID-19 outbreak. Quantitative variables were analyzed for descriptive statistics while qualitative data were summarized into emerging themes. Nurse leaders played a key role in motivating nurses despite response hesitancy due to risk of infection. Ensuring compliance to infection prevention and control standards was a key responsibility for all nurse leaders. Challenges included their late involvement in planning for service delivery, lack of dedicated resources for performing supervisory functions and the absence of a nursing operational plan for COVID-19. The inability to provide for psychological needs of nurses and unclear incentives policy were important factors for the lack of motivation. Enhanced interprofessional collaboration, professional development in critical care nursing, change management and expanded partnerships with community organizations were among opportunities identified. The role of nurse leaders can be maximized by ensuring their early involvement in strategic planning. A funded operational plan inclusive of dedicated resources for monitoring and supervisory functions of the nurse leaders is indispensable. To sustain motivation, facilities for psychological support, medical care, mentoring and a clear policy on incentives are required, as well as, a continuous professional development programme that addresses competences in nursing leadership and critical care.
\end{abstract}

Keywords: Nursing Leadership, Management, COVID-19 Response, Challenges, Opportunities

\section{Introduction}

In February 2020, the World Health Organization (WHO) designated the disease caused by a novel coronavirus to be coronavirus disease 2019 (COVID-19). The disease was characterized as a pandemic on 11 March 2020 in order to emphasize the gravity of the situation and to urge all countries to take action in detecting infection and preventing spread (Cucinotta and Vanelli, 2020). To date, the world continues to grapple with the COVID-19 pandemic. Zambia recorded its first cases of COVID-19 in March 2020. By August 2020, Zambia had reported 9,186 cases and 8,065 (87.7\%) of them had recovered, 861 were classified as active cases, with 76 COVID-19 deaths and 182 COVID-19 associated deaths. (MOH and ZNIPH, 2020). In June 2021, there were 129,033 accumulative cases, 108,960 recovered cases, 1,004 deaths and 1,644 COVID-19 related deaths (MOH and 
ZNIPH, 2021). While COVID-19 continues to spread in the community, the Zambian Government continues to aggressively promote community mitigation measures (Mulenga et al., 2021). It has been acknowledged that nurses are intermediaries who can help build trust between health care institutions, community organizations and residents. They not only provide skilled health care services, but tend to be the closest to the patient and their family caregivers and are the most aware of their broader psychosocial and health care needs (Butler and Diaz, 2017). Experience elsewhere on the COVID-19 crisis so far indicates that nurse leaders will continue to provide support in the interest of population safety (Rosser et al., 2020).

A nurse leader is a professional nurse who influences and coordinates patients, families and health care teams for the purpose of integrating the nursing care to achieve positive patient and public health outcomes (WHO, 2020; Morris, 2012). In the Zambian context, nurse leaders operate at various levels of the health system, which include the national level or Ministry of Health level, provincial, district and health facilities levels. The COVID-19 pandemic provides an opportunity to strengthen nursing leadership efforts towards the reduction of morbidity and mortality from this outbreak. It is recommended that nurse leadership must be developed at country, regional and global levels in order to accord nurses the opportunities to strengthen their leadership potential (Curtis et al., 2011). Leadership is tied to social responsibility and good citizenship, which connects nurses' professional and ethical responsibilities to champion the human right to health (WHO, 2021). Infectious diseases pose a major public health risk to communities and providers of health services and nurses provide holistic care to individuals, families and communities in health facilities and in the community (Corless et al, 2018).

There is an affirmation on the importance of nursing leadership in the early recognition of communicable diseases and calls on nursing leaders in each country to develop a coordinated response network for emerging or re-emerging infections (Corless et al, 2018) Such a network should be based on a grounds-up approach incorporating frontline health workers and communities since they are likely to be the first to recognize symptomatic individuals (WHO, 2020). In the recent past, there have been outbreaks such as Severe Acute Respiratory Syndrome (SARS) in 2003, Ebola virus in 2014, the Middle East Respiratory Coronavirus (MERS-CoV) in 2015 and Zika virus in 2016. In these outbreaks, nurses have played a pivotal role as part of teams managing epidemics that threaten health across the globe (Coster, Watkins and Norman, 2018; Dran, 2018; Wilson and Nguyen, 2017; Kollie et al, 2017; Sagar, 2015; WHO, 2020).

The delivery of nursing services entails that the role nurses must play affirms the leadership role in protecting communities they serve while maintaining their safety and that of others. To be effective especially during pandemics, nurses need the necessary support to carry out their work in order to remain providing the much needed nursing services (Lee and Kang, 2020). Therefore, nursing leadership should ensure that nurses have the necessary materials to do their work by engaging in strategic planning, coordination and implementation of nursing services. In a Ministerial Statement of 14 March 2020, the Zambia Ministry of Health announced comprehensive measures, which included strengthening infection prevention and control, procurement of disinfectants and Personal Protective Equipment (PPE), such as gloves, face masks, aprons and hand hygiene supplies (MOH and ZNIPH, 2020). With an increased surge of health worker recruitment, it was critical that material requirements matched the number of health workers and that adequate stocks were guaranteed.

Although issues relating to nursing leadership in pandemics can be broad, specific elements in the literature emphasize disease surveillance, communication, training, PPE, professional psychological support and job safety, monitoring and supervision of infection control collaborative teamwork and partnerships ( $\mathrm{MOH}$ and ZNIPH, 2020). Nurse leaders need to pay attention to the safety of nurses and patients. COVID-19 is highly transmissible and nurses are not always protected to the highest standards, usually due to the shortage of PPE. This puts them at risk of contracting the virus and unknowingly infecting vulnerable patients in the health facility, or their healthy family members, thereby contributing to the spread of the disease (Jones et al., 2008). In previous pandemics, PPE have been shown to be predictors of nurse's willingness to work (WHO, 2021). It is essential that staff understand the purpose of PPE and its role as part of a system to reduce disease transmission from patients to staff and other patients (Nightingale College, 2020). Training and skills in appropriate use of PPE are important because overuse of PPE is a form of misuse which can deplete limited stocks, lead to shortages and increased infection risk to staff (MOH and ZNIPH, 2020). In fact, during epidemics and pandemics, nurses are not only experiencing an increase in volume and intensity of their work, but are having to accommodate new protocols and a very "new normal" (Cook, 2020). They may have concerns over shortages of staff, PPE, unfamiliar settings or systems of care and lack of organizational support which contribute to stress (Maben and Bridges, 2020). Conflicts between health workers' responsibility to care for the ill and their right to protect themselves from a potentially lethal virus have also been reported as some of the stressors (Kim, 2018). A recent study in Wuhan, China, found that health workers had a strong spirit of treating patients with COVID19 because they had PPE, reasonable work schedules, an effective communication environment, monitoring and 
supervision of infection control and professional psychological support, all these factors improved experiences (Chen et al., 2005). Nurse leaders during the current pandemic indicate that the highest priority for a leader is the safety of the workforce, including availability of PPE, appropriate staffing and reducing exposure to infections during patient care (Xiong and Peng, 2020). Important coping strategies include religion, a sense of serving the community, peer support and family support. Training which builds health worker confidence in providing care, provision of equipment to do the job safely, social media platforms which help health workers deal with challenges, workshops that provide ways to deal with the stigma associated with being a health worker and monetary risk allowances which motivate staff to work in facilities and provide an additional income source are also important (Guldbrandsson and Bremberg, 2020). In the conditions of increasingly stressful work environments, paying attention to nurses' mental wellbeing is critical and emphasis should be placed on the need to recognize the inherent stress and emotional strain that nurses bear on behalf of society (Cook, 2020).

Nurses contribution to disease surveillance is part of their daily routines and becomes more important during pandemics. Early detection of suspected diseases as well as reporting and monitoring trends as part of disease surveillance is an integral part of the health care system. In health facilities in Zambia, the nurse-in-charge is responsible for immediate notification of epidemic diseases and for compiling and submitting weekly and monthly reports on suspected and confirmed cases and mortality on notifiable infectious diseases seen at the health facility. One study conducted in Zambia concluded that operationalized epidemic preparedness and response requires full-time staff and budget dedicated to disease surveillance at all levels. Inadequate trained human resources, poor infrastructure and coordination were identified as challenges (Raven et al., 2018). In Zambia, it was revealed that over a 12-month period, about $27.3 \%$ of the health workers either infrequently or never reported cases of disease that required mandatory reporting. The reasons given were that the process of reporting was cumbersome because the reporting forms were too many and complicated. The health workers further stated that Integrated Disease Surveillance Response (IDSR) implementation lacked prompt feedback from the district managers and all the health facilities lacked adequate resources. For example, between 11.1 to $44.4 \%$ of health facilities lacked one or more types of reporting forms, facilities lacked stable electrical power and internet network connectivity was poor and yet, about $51.5 \%$ health workers relied on mobile phones for sending reports (Mandyata et al., 2017). The role of a functional surveillance system, with nurses as generators of health data is critical during a pandemic such as COVID-19 and many countries face challenges that could impinge proper disease surveillance.
Nurse leaders should not only communicate to their staff and patients but should also communicate to family members and communities on health risks. Strategies for nurse leaders must include being available for nursing staff, practicing open communication and taking personal interest in staff. Nurse leaders who strive to exercise these strategies are likely to improve work engagement levels of team members (Haakonde et al., 2018). Communication is also essential for social mobilization (Mandyata et al., 2017). During pandemics, infrequent and non-transparent communication leads to spread of misinformation resulting in heightening of fears and chaos. By promoting nurse leaders as health content experts, both the press and the public would not only learn more about the nursing profession, but would also learn to value nurses as health educators and health care leaders (Rebmann and Carrico, 2017). In Lofa County, Liberia, education and awareness-induced behavior change in the population was instrumental in curtailing the Ebola outbreak (Fast et al., 2015). The Johns Hopkins Center for Communications shares five lessons on communication on the current COVID-19 pandemic. These are building trust, having one set of messages, countering myths and misinformation, promote action and being empathetic (Krenn, 2020). This is also supported by other studies (Leary, 2017). Whilst people in Zambia have gained knowledge on various aspects of COVID-19 prevention and control, knowledge gaps still exist. Communicating messages on pandemics should be a continuous process and not a one off activity (Nightingale College, 2020). These important lessons provide the much needed evidence for improving nursing leadership on communication in pandemics and the need to ensure appropriate use of Information Communication Technology (ICT).

Every infectious disease outbreak brings with it training needs, especially on infection prevention and control. Nursing leadership ought to ensure that nurses are competent and skilled to carry out their work effectively and safely. In addition to training on use of PPE, other elements to reduce cross-infection include understanding when dealing with patients, visitors or staff who have or have not been exposed to COVID-19 entering hospitals without reason, handwashing and personal hygiene, managing patients with known or suspected COVID-19 in isolation, cleaning regimens of surfaces and equipment, appropriate disposal of all single-use equipment, decontamination of reusable equipment and appropriate waste management $(\mathrm{MOH}$ and ZNIPH, 2020). This requires a pandemic preparedness and response plan. For example, an Ebola preparedness and response plan addressed the key areas of coordination and resource mobilization, epidemiology, surveillance and laboratory, case management and infection prevention, social mobilization and media communication, logistics and recovery (Jones et al., 2020). In Sierra Leone, training at the National Ebola Training Academy dealt with every 
aspect of the disease that was useful for the survival of patients and health care workers. It aimed at improving understanding of Ebola. The information provided during training decreased practitioners' anxiety during patient care. The expert knowledge and skills of health practitioners made the difference in controlling the Ebola epidemic in Sierra Leone (MOH and ZNIPH, 2020). A well-articulated training strategy and its implementation would ensure that nurses acquire the right competencies to respond to COVID-19 and other future epidemics and pandemics. Nurse leaders must be aware of national policies, strategies and guidelines in order to develop appropriate training for the nursing workforce during pandemics. Establishing order, predictability, direction, own sense of calm, focus and self-assurance play a significant role in working with staff. Nurse leaders need to recognize that organizational strategies change and it is important to have a plan of approaches before responding. This plan should include; information, policies, regulations and resources needed (Jones-Konneh et al., 2017). This would form the basis for monitoring and supervision of nurses on infection control. Since nurses have the most consistent day-to-day contact with patients, it is crucial that they adhere to standard infection control and transmission-based precautions to prevent the spread of healthcare-associated infections. Lack of consistency and non-compliance with infection prevention including lapses in PPE usage can put nurses at risk for occupational exposure or contribute to healthcare-associated disease transmission. The reasons for these lapses should be identified and addressed by the nurse leader so that nurses are competent on infection prevention and control. This offers an opportunity to demonstrate proper adequate knowledge and safe practice on infection control and practice (Haakonde et al., 2018). Aspects of monitoring by the nurse leader may include an infection control plan, facility risk assessment, written goals on how to follow these, alignment with infection control policies, assignment of responsibilities, staff education, adherence to national guidance and standards, monitoring prevention practices, keeping track of outbreaks, analysis of root causes and appropriate use of isolation precautions (USDVA, 2020). The nurse leader must understand the unique aspects of caring for highly infectious patients as to better support nursing staff.

To be able to deliver quality nursing services during pandemics nurse leaders recognize that nurses' sphere of influence as healthcare professionals goes beyond the individuals, families, groups and communities they work with. It extends throughout the health sector to other practitioners, allied health colleagues and those with policy, management and fiscal responsibilities (WHO 2021). As the largest cadre of the health workforce in most countries, as well as a profession that is dedicated to prevention and alleviation of suffering, nurses must be integrally involved with interprofessional teams and communities for epidemic and pandemic preparedness (Smith et al., 2017). A hallmark of the transformed health system is a new level of collaboration across the health professions, including physicians, medical licentiates, nurses, social workers, pharmacists and medical assistants (Fraher et al., 2015). Collaborative interdisciplinary care has been shown to result in better outcomes for patients (MOH and ZNIPH, 2020).

In pandemics, the successful response is often dependent upon the degree of collaboration, coordination and shared decision making occurring among a wide-ranging group of public and private stakeholders in the community. Evidence suggests that timely enhancement of the existing community partnerships enable successful implementation of response activities with local community support (Alrwaihi et al., 2018). Community participation is essential in the collective response to COVID-19, from compliance with "lockdowns", to the steps that need to be taken as countries ease restrictions, to community support through volunteering (Gupta, 2011). By implementing the whole-of-society approach to pandemic preparedness and response, governments can enhance their ability to manage future outbreaks (Marston et al., 2020). Nurse leaders bring nurses together as a team, making sure they communicate efficiently with each other and with other multidisciplinary team members, patients and the patient's families. Clear communication and collaboration are key to maintaining high standards of quality care and safety (Jones et al., 2008; Schwartz and Yen, 2017).

\section{The Study Aim}

The aim was to describe the nursing leadership contribution, challenges and opportunities to the COVID-19 pandemic response in Zambia.

\section{Methods}

A cross-sectional survey involving two groups of nurse leaders was conducted between 1 November 2020 and 20 February 2021. Participants in the study were selected purposefully by virtue of their positions in the institutions or the health facilities. The first group was from national level (Ministry of Health headquarters), Provincial Health Offices (PHO) and District Health Offices (DHO). The second group were nurse leaders serving at hospitals and health centers. Six provinces were included in the study and were selected on the basis of epidemiology and risk for COVID-19. In each province, three districts were selected. The health facilities selected were all level 3 hospitals, the provincial hospitals, the district hospitals and three health centers in each district. At provincial and district levels, selection of the health facility was biased towards likelihood of seeing COVID-19 cases, such as, closeness of the district to border entry points. 


\section{Data Collection Tools}

Regarding nurse leaders at national, provincial and district health offices, telephone interviews were conducted by the Principal Investigator using a standard questionnaire. The focus of the interview was on leadership and influence, involvement in policy development, policy implementation, planning for COVID-19 services (including human resources) at national, provincial and district levels and coordination with partners. Concerning the nurse leaders working at health facilities, self-administered questionnaires were completed by the participants. The questionnaire covered aspects of their roles and responsibilities in relation to COVID-19, planning and delivery of services, monitoring and supervision of staff, involvement in policy advice and overall experience with the COVID-19 outbreak.

\section{Study Setting}

This study was conducted in 6 provinces. Administratively, there are 10 provinces and 107 districts in Zambia. Lusaka and Copperbelt Provinces are predominantly urban whereas the remaining provinces, Central, Eastern, Luapula, Muchinga, Northern, NorthWestern, Southern and Western are predominantly rural (Luwabetwa et al., 2017). Quarantine centres for COVID-19 were designated by the government and patients requiring hospitalization were treated at selected hospitals.

\section{Data Analysis}

Quantitative variables were extracted from the self-administered questionnaire and the interviews were entered into Microsoft Excel spread sheets and analyzed with descriptive statistics. Qualitative data from both the questionnaires and the interviews were summarized into emerging themes. With respect to the nursing leaders at national, provincial and district levels, the following areas were addressed; employment status and responsibilities, leadership and influence, planning and delivery of COVID-19 nursing services, monitoring of policy implementation, information technology, management of nursing services ending with a narrative component of their experiences during COVID-19 pandemic. The thematic areas for nurse leaders at the health facilities were; roles and functions, characteristics of a nurse leader during COVID-19 pandemic, competencies and involvement in training, information technology, recognition and appreciation of nurse leaders by professionals and general public, roles in overseeing COVID-19 nursing services, involvement in the establishment of national standards, monitoring and supervision of COVID-19 nursing services, ensuring compliance, psychological support to nurses, collaboration, partnerships and their contribution and overall challenges and opportunities.

\section{Results}

\section{Part 1: Nursing Leadership at National, Provincial and District Levels}

\section{Employment and Main Responsibilities}

A total of 21 nurse leaders were interviewed. Five were at national level, nine at provincial level and seven at district level. Twelve $(57.1 \%)$ had been in their current positions for more than five years, seven $(33.3 \%)$ for $1-5$ years. The remaining two, one at national and one at district level, had been in their positions for less than a year.

The main responsibilities of the nurse leaders at all levels are given in Table 1. These were, supervision of nursing personnel and services (95.2\%) followed by coordination of nursing services $(85.7 \%)$, monitoring and evaluation of nursing services $(76.2 \%)$, operational research, activity planning, budgeting and implementation (30\%). Collaboration with other departments was the least mentioned and only mentioned by 5 of the 9 provincial leaders. All five national level leaders indicated that their main responsibilities were capacity building, mentoring, provision of technical support, monitoring and evaluation of nursing services. Quality assurance, supervision and research were stated by four $(80.0 \%)$ while policy translation and dissemination and coordination of nursing services by three $(60.0 \%)$. Only one $(20.0 \%)$ of the national level nurse leaders indicated planning, budgeting and implementation as their main responsibilities.

At provincial level, all nine respondents reported supervision as their main role and among these, eight $(88.9 \%)$ included coordination of nursing services as well as monitoring and evaluation. Policy translation and dissemination was specified by six $(66.7 \%)$, while quality assurance and collaboration by five $(55.5 \%)$ respondents. Capacity building, activity planning, budgeting and implementation were reported by four $(44.4 \%)$ of the provincial level leaders and only three (33.3\%) indicated that operational research was one of their responsibilities. At the district level, supervision and coordination was listed by all leaders as a main responsibility. Other responsibilities at district level were monitoring and evaluation of nursing services by three (42.9\%), quality assurance, activity implementation, capacity building, mentoring and technical support by two $(28.5 \%)$ and policy translation and dissemination by one $(14.3 \%)$. Research was not named by any of the district level leaders. With the onset of COVID-19, major changes in responsibilities were noted by leaders at national level and five (56\%) of the provincial leaders and at district level only three (43\%) reported major changes. The major changes were due to the intensity of the work especially in the areas of care, training, nursing workforce management and to some extent teamwork at the provincial level. 


\section{Nursing Leadership Influence and Policy During Epidemics/Pandemics}

Nurse leaders at all levels were asked if there was a policy or a strategic plan for nursing during epidemics (Table 2). Seventeen $(81 \%)$ of all leaders indicated that there was only a general national plan for epidemics. However, they all said that all health facilities were expected to have their own epidemic committees. Only seven $(33 \%)$ of the leaders stated that temporary COVID-19 plans were available. Most (90\%) of the leaders indicated that there was a plan to review the National Strategic Plan on nursing in order to strengthen the infection prevention and control component. Engaging nurses in COVID-19 services was reported by $(81 \%)$, leading and establishing nursing structures, capacity building, collaboration and networking with other partners by $(71.4 \%)$. The setting of nursing strategic directions was primarily for national leaders, while engaging the community including advocacy was mentioned by $93.3 \%$ of the provincial and district nurse leaders. The only other functions indicated by district level leaders were daily reporting and supervision. Participation in COVID-19 screening was reported by two provincial leaders and two district nurse leaders.

\section{Planning and Delivery of COVID-19 Services}

Table 3, presents the extent of involvement of nurse leaders in various COVID-19 activities. In the area of training activities on COVID-19, 13 of the 21 (61.9\%) leaders participated in COVID-19 capacity building activities. These activities included other health workers as well. More than $70 \%$ of the leaders reported that the topics covered in these capacity building activities were, infection prevention and control, case management and surveillance. Contact tracing, media communication and social mobilization were indicated in $52-66 \%$ of the respondents. The reason given was that these issues are normally carried out by other departments in the Ministry of Health. As regards planning national program standards, all national leaders stated that they were partially or indirectly involved. This involvement was however restricted to reviewing the nursing sections of the standards and to attending meetings. At provincial level, only three leaders mentioned direct involvement while only one leader at district level had been fully involved. Overall $(52 \%)$ of the leaders were not involved in establishing national programme standards.

\section{Information Technology Use}

The use of technology in planning and delivering nursing services related to COVID-19 was explored during the study (Table 4). The most common use of technology for nursing services was communication $(90.5 \%)$, followed by virtual meetings, information search and reporting in $52.4 \%$. The use of technology for documentation was only used in 33\%. Nurse leaders at national level use all five key areas of ICT. The information technology medium used included social media (95.2\%), e-mail (66.7\%), mobile phones $(57 \%)$ and internet platforms was used in (52.4\%). The social media application "WHATSAPP" was the most common application used for establishing groups.

\section{Monitoring of Policy Implementation}

Nurse leaders were asked how they monitored implementation of the policy for delivery of COVID-19 nursing services (Table 5). All leaders at national and district levels monitored the delivery of nursing services on a daily basis, while at the provincial level five indicated monitoring occurred on a daily basis. The remaining stated that they only did so when logistics were available. Concerning reports on COVID-19 from the health facilities, all leaders at national level received regular reports. At provincial level, five out of nine received regular reports and the remaining four received the reports during monthly management meetings. At district level, six respondents indicated that they received regular reports and only one mentioned that reports were received monthly. Regular reports were either daily for the majority and for others, they received them weekly. However, the provincial level nurse leaders noted apathy in reporting because of high staff turnover. Aspects covered in the monitoring of health facilities were specified. The number of nurses at health facilities, adequacy of general supplies including PPEs were monitored at $(85.6 \%)$, followed by the number and type of facility involved in COVID-19, compliance to infection prevention and control and the number of health workers infected with COVID-19 (81.0\%). Appropriate use of supplies and general prevention measures were mentioned by $66.7 \%$. Mental health and burnout of nursing personnel were only mentioned by $47.6 \%$. Two provincial nurse leaders could not monitor because of confidentiality issues.

\section{Management of the Nursing Workforce}

In terms of the management of the nursing workforce, all nurse leaders at national level were aware of the general policy on occupational health and safety, while at the provincial and district levels, only 6 out of $15(40 \%)$ were aware of the existence of the policy. One provincial respondent reported seeing the guidelines on what to do when one is infected with COVID-19. With regards to incentives, all nurse leaders (except one at national level) were aware of incentives for nurses working in COVID-19 care areas. Four indicated incentives were provided (three at national, one at provincial). The incentives were primarily food hampers and personal hygiene items for nurses working with COVID-19 patients. A financial risk allowance of $2 \%$ of gross salary had been promised. However, 16 out of $21(76.2 \%)$ indicated that incentives were promised but not provided (Table 6). 
Table 1: Responsibilities of nurse leaders at national, provincial and district level

\begin{tabular}{|c|c|c|c|c|c|c|c|c|c|}
\hline & \multirow[b]{2}{*}{ Variable } & \multicolumn{2}{|c|}{ National } & \multicolumn{2}{|c|}{ Provincial District } & \multicolumn{4}{|c|}{ Totals } \\
\hline & & $\mathrm{n}$ & $\%$ & $\mathrm{n}$ & $\%$ & $\mathrm{n}$ & $\%$ & $\mathrm{n}$ & $\%$ \\
\hline & Total number of leaders & 5 & & 9 & & 7 & & 21 & \\
\hline \multirow[t]{10}{*}{1} & Main responsibilities & & & & & & & & \\
\hline & a) Policy translation and dissemination & 3 & & 6 & & 1 & & 10 & 47.6 \\
\hline & b) Supervision of nursing personnel & 4 & & 9 & & 7 & & 20 & 95.2 \\
\hline & c) Quality assurance and adherence monitoring & 4 & & 5 & & 2 & & 11 & 52.4 \\
\hline & d) Coordination of nursing services & 3 & & 8 & & 7 & & 18 & 85.7 \\
\hline & e) Collaboration with other departments & - & & 5 & & - & & 5 & 23.8 \\
\hline & f) Activity planning, budgeting, implementation & 1 & & 4 & & 2 & & 7 & 30.0 \\
\hline & g) Capacity building, technical support \& mentorship & 5 & & 4 & & 2 & & 11 & 52.4 \\
\hline & h) Research & 4 & & 3 & & - & & 7 & 30.0 \\
\hline & i)Monitoring and evaluation of nursing services & 5 & & 8 & & 3 & & 16 & 76.2 \\
\hline \multirow[t]{4}{*}{2} & Changes in responsibilities because of COVID-19 & & & & & & & & \\
\hline & a) Major changes & 5 & & 5 & & 3 & & 13 & 61.9 \\
\hline & b) Minimal change & & & 3 & & & & 3 & 14.3 \\
\hline & c) No change & & & 1 & & 4 & & 5 & 23.8 \\
\hline
\end{tabular}

Table 2: Nurse leadership influence and specific COVID-19 related functions

\begin{tabular}{|c|c|c|c|c|c|c|c|c|c|}
\hline & \multirow[b]{2}{*}{ Variable } & \multicolumn{2}{|c|}{ National } & \multicolumn{2}{|c|}{ Provincial } & \multicolumn{2}{|c|}{ District } & \multicolumn{2}{|c|}{ Totals } \\
\hline & & \# & $\%$ & \# & $\%$ & \# & $\%$ & \# & $\%$ \\
\hline & Total number of leaders & 5 & & 9 & & 7 & & 21 & \\
\hline \multirow[t]{3}{*}{1.} & Strategic direction for nursing during epidemics & & & & & & & & \\
\hline & a) Only general national epidemic guidelines & 5 & & 7 & & 5 & & 17 & 81.0 \\
\hline & b) Temporary strategic COVID-19 nursing plan available & 3 & & 2 & & 2 & & 7 & 33.3 \\
\hline \multirow[t]{3}{*}{2.} & Update of Nursing Strategic Plan & & & & & & & & \\
\hline & a) No revision done & 5 & & 8 & & 7 & & 20 & 95.2 \\
\hline & b) Regular/daily updates on current status & - & & 1 & & - & & 1 & 5.0 \\
\hline \multirow[t]{7}{*}{3.} & Functions during COVID-19 Outbreak & & & & & & & & \\
\hline & a) Setting nursing strategic direction & 5 & & 2 & & 3 & & 10 & 47.6 \\
\hline & b) Leading and establishing nursing structures & 5 & & 6 & & 4 & & 15 & 71.4 \\
\hline & c) Engaging nurses in COVID-19 services & 5 & & 6 & & 6 & & 17 & 81.0 \\
\hline & d) Involvement in capacity building & 5 & & 6 & & 4 & & 15 & 71.4 \\
\hline & e) Collaboration and networking with other partners & 5 & & 6 & & 4 & & 15 & 71.4 \\
\hline & f) Engaging the community including advocacy & - & & 8 & & 6 & & 14 & 66.7 \\
\hline \multirow[t]{4}{*}{4.} & Other functions & & & & & & & & \\
\hline & a) Sensitization on COVID-19 to patients & - & & - & & - & & - & \\
\hline & b) Daily reporting (morning and evening) & - & & - & & 2 & & 2 & 10.0 \\
\hline & c) Participation and supervision of COVID-19 screening & - & & - & & 2 & & 2 & 10.0 \\
\hline
\end{tabular}

Table 3: Planning and delivery of COVID-19 nursing services

\begin{tabular}{|c|c|c|c|c|c|c|c|c|c|}
\hline & \multirow[b]{2}{*}{ Variable } & \multicolumn{2}{|c|}{ National } & \multicolumn{2}{|c|}{ Provincial } & \multicolumn{2}{|c|}{ District } & \multicolumn{2}{|c|}{ Totals } \\
\hline & & \# & $\%$ & $\#$ & $\%$ & $\#$ & $\%$ & \# & $\%$ \\
\hline & Total number of leaders & 5 & & 9 & & 7 & & 21 & \\
\hline 1 & Training activities conducted on COVID-19 & 3 & & 6 & & 6 & & 13 & 61.9 \\
\hline \multirow[t]{8}{*}{2} & Topics covered during training & & & & & & & & \\
\hline & a) National standards for infection control & 3 & & 8 & & 5 & & 16 & 76.2 \\
\hline & b) Infection control and prevention & 3 & & 8 & & 5 & & 16 & 76.2 \\
\hline & c) Case management & 3 & & 8 & & 4 & & 15 & 71.4 \\
\hline & d) Surveillance & 3 & & 8 & & 4 & & 15 & 71.4 \\
\hline & e) Contact tracing & 3 & & 7 & & 4 & & 14 & 66.7 \\
\hline & f) Social mobilization & 3 & & 5 & & 3 & & 11 & 52.4 \\
\hline & g) Media communication & 3 & & 7 & & 2 & & 12 & 57.1 \\
\hline \multirow[t]{4}{*}{3} & Involvement in establishing national programme standards & & & & & & & & \\
\hline & a) Fully involved & & & 1 & & & & 1 & 5.0 \\
\hline & b) Partially/indirectly & 5 & & 2 & & & & 7 & 33.3 \\
\hline & c) Not involved & & & 5 & & 6 & & 11 & 52.4 \\
\hline \multirow[t]{4}{*}{4} & Areas of involvement & & & & & & & & \\
\hline & a) Reviews of plans for nursing services & 5 & & 3 & & 1 & & 9 & 42.9 \\
\hline & a) Participation in meetings & 5 & & 1 & & & & 6 & 28.6 \\
\hline & b) Budgeting & - & & 1 & & & & 1 & 5.0 \\
\hline
\end{tabular}


Table 4: Information Technology (IT) use

\begin{tabular}{|c|c|c|c|c|c|c|c|c|c|}
\hline & \multirow[b]{2}{*}{ Variable } & \multicolumn{2}{|c|}{ National } & \multicolumn{2}{|c|}{ Provincial } & \multicolumn{2}{|c|}{ District } & \multicolumn{2}{|c|}{ Totals } \\
\hline & & \# & $\%$ & $\#$ & $\%$ & $\#$ & $\%$ & \# & $\%$ \\
\hline & Total number of leaders & 5 & & 9 & & 7 & & 21 & \\
\hline \multirow[t]{6}{*}{1} & Technology use for nursing related services & & & & & & & & \\
\hline & a) Communication & 5 & & 7 & & 7 & & 19 & 90.5 \\
\hline & b) Documentation/Recording & 5 & & 1 & & 1 & & 7 & 33.3 \\
\hline & c) Virtual meetings, online forums & 5 & & 4 & & 2 & & 11 & 52.4 \\
\hline & d) Information searches and sharing & 5 & & 4 & & 2 & & 11 & 52.4 \\
\hline & e) Reporting & 5 & & 3 & & 3 & & 11 & 52.4 \\
\hline \multirow[t]{5}{*}{2} & $\begin{array}{l}\text { IT methods used for ensuring } \\
\text { efficient services }\end{array}$ & & & & & & & & \\
\hline & a) Social media & 5 & & 8 & & 7 & & 20 & 95.2 \\
\hline & b) E-mail & 3 & & 8 & & 3 & & 14 & 66.7 \\
\hline & c) Mobile phones & 2 & & 8 & & 2 & & 12 & 57.1 \\
\hline & d) Internet platforms & 4 & & 6 & & 1 & & 11 & 52.4 \\
\hline
\end{tabular}

Table 5: Monitoring of policy implementation

\begin{tabular}{|c|c|c|c|c|c|c|c|c|c|}
\hline & \multirow[b]{2}{*}{ Variable } & \multicolumn{2}{|c|}{ National } & \multicolumn{2}{|c|}{ Provincial } & \multicolumn{2}{|c|}{ District } & \multicolumn{2}{|c|}{ Totals } \\
\hline & & $\#$ & $\%$ & $\#$ & $\%$ & \# & $\%$ & $\#$ & $\%$ \\
\hline & Total number of leaders & 5 & & 9 & & 7 & & 21 & \\
\hline \multirow[t]{3}{*}{1 . } & Monitoring of delivery of nursing services & & & & & & & & \\
\hline & a) Daily monitoring (2 times a day minimum) & & & 5 & & 6 & & 11 & 52.4 \\
\hline & b) Only when logistics were available & & & 2 & & & & 2 & 10.0 \\
\hline \multirow[t]{4}{*}{2.} & Regular reports from facilities on supplies and human resources & & & & & & & & \\
\hline & a) Regular reports received (frequency varied) & 5 & & 5 & & 6 & & 16 & 76.2 \\
\hline & b) Monthly reports (during management meetings) & & & 4 & & 1 & & 5 & 23.8 \\
\hline & c) Apathy noted because of high staff turnover & & & 3 & & & & 3 & 14.3 \\
\hline \multicolumn{10}{|c|}{ 3. Aspects covered in monitoring of health facilities } \\
\hline & a) Number and type of facilities involved in COVID-19 & 5 & & 6 & & 6 & & 17 & 81.0 \\
\hline & b) Adequacy of supplies at facilities including PPE & 5 & & 7 & & 6 & & 18 & 85.6 \\
\hline & c) Appropriate use of supplies and prevention measures & 2 & & 5 & & 7 & & 14 & 66.7 \\
\hline & d) Compliance with infection control at the facilities & 4 & & 6 & & 7 & & 17 & 81.0 \\
\hline & e) Number of nursing personnel at facility including students & 4 & & 7 & & 7 & & 18 & 85.6 \\
\hline & $\begin{array}{l}\text { f) Number of health workers infected with COVID-19 } \\
\text { at the health facility }\end{array}$ & 3 & & 7 & & 7 & & 17 & 81.0 \\
\hline & f) Mental health and burn-out of nursing personnel & 4 & & 6 & & & & 10 & 47.6 \\
\hline
\end{tabular}

Table 6: Nursing workforce management

\begin{tabular}{|c|c|c|c|c|c|c|c|c|c|}
\hline & \multirow[b]{2}{*}{ Variable } & \multirow{2}{*}{\begin{tabular}{l} 
National \\
\hdashline$\#$ \\
---
\end{tabular}} & \multirow[b]{2}{*}{$\%$} & \multicolumn{2}{|c|}{ Provincial } & \multicolumn{2}{|c|}{ District } & \multicolumn{2}{|c|}{ Totals } \\
\hline & & & & \# & $\%$ & \# & $\%$ & \# & $\%$ \\
\hline \multirow{4}{*}{1} & Total number of leaders & 5 & & 9 & & 7 & & 21 & \\
\hline & Management of nursing workforce & & & & & & & & \\
\hline & $\begin{array}{l}\text { a) Awareness on policy or strategy } \\
\text { on occupational safety }\end{array}$ & 5 & & 2 & & 4 & & 11 & 52.4 \\
\hline & $\begin{array}{l}\text { b) Guidelines for occupational } \\
\text { exposure to COVID-19 }\end{array}$ & 0 & & 1 & & & & 1 & 5.0 \\
\hline \multirow[t]{3}{*}{2} & $\begin{array}{l}\text { Incentives for nurses working in } \\
\text { COVID-19 risk areas }\end{array}$ & 4 & & 9 & & 7 & & 20 & 95.2 \\
\hline & a) Incentives provided & 3 & & 1 & & 0 & & 4 & 20.0 \\
\hline & $\begin{array}{l}\text { b) Incentives promised but not } \\
\text { implemented }\end{array}$ & 1 & & 8 & & 7 & & 16 & 76.2 \\
\hline
\end{tabular}




\section{Overall Experiences of Nurse Leaders in Responding to COVID-19}

The overall experiences of nurse leaders at national, provincial and district levels are summarized in Table 7. Experiences in partnerships and engagement of nurse leaders that were important to the delivery of COVID-19 services are presented in Table 8 .

The leaders expressed need for greater involvement of partners to ensure understanding of work areas and for nurse leaders to understand partner's mandates. This would also enable partners to provide specific support to nursing services and minimize duplication of efforts and improve communication. One area suggested was the setting up of "Taskforces" where objectives, plans, activities and feedback are shared. Transparency and accountability on resources provided by partners in support of the COVID-19 response were perceived as an imperative. Across all nursing leadership levels, they expressed need for engagement in planning and providing input in all key meetings as early as possible during a pandemic such as, being involved in the process of resource mobilization. Collaboration, interdisciplinary work modalities and sharing of experiences were viewed as important aspects in responding to epidemics/pandemics. Such collaboration should be free of intimidation, where nurse leaders are treated as equals in management and recognized in the delivery of COVID-19 services to the patients and the community. Direct involvement in capacity building of nurse leaders was desired as an essential aspect of their professional growth. They indicated that trainers of trainers across all levels were needed and guidelines for nursing during epidemics were necessary and should be readily available. In order for them to perform better in their supervisory and monitoring functions, they also pointed out the urgent need to ensure logistics such as dedicated transport and communications facilities. Mentoring and psychological support to the staff they supervise and clarity on policy and implementation of incentives for those working in high risk environments and its implementation were needed.

The national level nurse leaders acknowledged that COVID-19 provided a new experience that highlighted the need for epidemic and pandemic preparedness. However, they felt that work was challenging even when there was an operational plan for nursing due to the limited role nurses have in decision making. Teamwork was viewed as indispensable and that communication was an important aspect of mobilizing nurses to participate in COVID-19 services. Technology played a useful role in accessing and sharing information with other nurse leaders. The COVID-19 experience also revealed that most nurses had no motivation to work on COVID-19 services due to lack of incentives. At the provincial level, leaders noted that being unprepared at the beginning of the pandemic increased infections amongst nurses due to lack of PPEs. Furthermore, inadequately prepared nurses and the shortage of nurses increased the workload which jeopardized the provision of quality care. Nurses were afraid of contracting the disease and were stigmatized by the community. Lack of incentives or tokens of appreciation, limited facilities and challenges in the use of information technology for work and communication were negative experiences. Nevertheless, the provincial leaders acknowledged the positive relationships they had cultivated with partners and that the Incidence Management System and the Zambia National Institute of Public Health helped reduce anxieties and overcame some challenges. On the other hand, the district level leaders lamented the lack of nursing plans, risk of exposure to infections and lack of appreciation, leaving nurses feeling neglected and making work difficult. The leaders at this level also alluded to similar experiences outlined by provincial nurse leaders such as inadequate staff, deployment of staff not oriented or trained on COVID-19, long working hours and the emotional and physical impact of COVID-19 on the staff and their families, which was not given priority by higher-level management. Finally, the nurse leaders proposed the changes that would be needed to improve their effectiveness in providing support to the COVID-19 outbreak response and other future epidemics (Table 9).

Across all three levels, support for logistics, communication and a fully funded operational plan were a necessity for their work. Incentives for nurses should be implemented and adequate staffing at health facilities should be ensured. Their participation in a continuous professional development programme that would address their training needs was also highlighted.

\section{Part 2: Nurse Leaders at Hospitals and Health Centres}

\section{Roles and Responsibilities}

A total number of 37 nurse leaders from six provinces participated in the study (Table 10). The respondents included 6 Registered Nurses, 24 Nursing Officers, 2 Provincial Nursing Officers, 2 Chief Nursing Officers and an Enrolled Nurse. The most common role in the fight against COVID-19 was organizing nursing services (70.3\%), infection control $(56.8 \%)$ and monitoring patient care (51.4\%). The role of infection control was higher at health center level study participants compared to those at hospital level. Monitoring of patient care was higher at hospital level $(60 \%)$ while at health center level it was $14.3 \%$. Other roles were reported by $30 \%$ or less of the nurse leaders.

\section{Key Daily and Routine Activities During Covid-19 and Key Characteristics for the Nurse Leader}

Key daily routine activities were similar between hospitals and health centers and the ideal characteristics needed for a nurse leader are given in Table 11. The activities included administrative duties, checking on COVID-19 precautions adherence (70.3\%) and 
routine spot-checks $(56.8 \%)$. Hospital and health center level nurse leaders outlined their main functions during the COVID-19 pandemic. Engaging nurses in COVID-19 services was reported by $81.1 \%$ of the respondents, developing nursing capacity (78.4\%), advocacy involving patients, family and community (73\%), leading and establishing nursing structures was overall at $73 \%$ but significantly higher among hospital level nurse leaders. Setting strategic directions for nursing services was at $66.7 \%$ among leaders at hospital level and $42.9 \%$ at health center level. Establishing collaboration and networking with other professions was reported at $43.3 \%$ among hospital level leaders and only $28.6 \%$ at the health center level. Regarding the views on the characteristics of a nurse leader during the COVID-19 pandemic, hospital level nurse leaders considered the nurse leader to be an educator $(60 \%)$ and be supportive $(56.7 \%)$, while health center level leaders considered empathy $(57.1 \%)$ as a key characteristic. Mentorship was specified by $43 \%$ and $14.3 \%$ of the hospital and health center leaders respectively. Advocacy was only mentioned by $40.0 \%$ of the hospital leaders.

\section{Involvement in Training and Competencies}

With respect to involvement in training of staff to be deployed to COVID-19 isolation centers, only $33 \%$ hospital leaders and $57.1 \%$ health center nurse leaders were involved (Table 12). Key topics covered included; the use of PPEs (48.6\%), infection prevention (45.9\%), case management $(42.9 \%)$, contact tracing $(21.6 \%)$ and waste management (18.9\%). In relation to competency in national standards for infection control, $(63.3 \%)$ of the nurse leaders at hospital level stated they were competent while at the health center level it was $100 \%$. For prevention and control of COVID-19, $63.3 \%$ hospital level nurse leaders indicated that they were competent while at health center level only $42.9 \%$ said they were competent. With regard to the management of COVID-19 cases, 50\% felt competent at hospital level and $57.1 \%$ at the health centers. Competency in communication was reported lowest $(35.1 \%)$. One respondent reported not being competent in any of the areas indicated. In terms of recognition and appreciation, only $27 \%$ felt they were recognized and appreciated by other health professionals and only $18.9 \%$ indicated appreciation by the public. One respondent indicated he/she was not competent in any of the 5 areas.

\section{Role in Overseeing COVID -19 Nursing Services}

The role of nurse leaders at hospitals and health centers in overseeing nursing services are shown in Table 13. Ensuring infection control was highest amongst both hospital and health center based nurse leaders $(66.7 \%$ and $57.1 \%$ respectively). Management of human resources was ranked higher among hospital nurse leaders compared to health center's $(63.3 \%$ versus $42.9 \%)$. However, training and capacity building was higher at health centers $57 \%$ as compared to $26.6 \%$ with hospital nurse leaders. Mentorship and provision of emotional support was low (at hospital level 30\% and health centers 28.0\%). The study also explored the extent to which nurse leaders were involved in specific COVID-19 activities. Only two of the hospital based leaders and one at the health center were involved in establishing standards for quality services for staff and patients. Involvement in recruitment of nurses was only reported by $33 \%$ of nurses at hospital level and none at the health centers. With regard to policy advice to the Ministry of Health, only $6(20 \%)$ of hospital level nurse leaders reported involvement.

\section{Information Technology Use}

Information technology use by the nurse leaders is given in Table 14. The most common use was for communication (46.7\% by hospital $42.9 \%$ at health centers). Use for reporting, was $40 \%$ at the hospital and $57.1 \%$ by health center nurse leaders. Technology use for information searches was limited $(16.7 \%$ at hospital level and $28.6 \%$ at health care center level).

\section{Monitoring and Supervision}

Nurse leaders were asked to indicate if and how COVID-19 infection prevention and control standards were monitored (Table 15). Monitoring was higher at the hospital level $(86.7 \%)$ and $57.1 \%$ at health centers. In terms of non-compliance to infection prevention and control standards, these were monitored more at the health centers $(85.7 \%)$ compared to $73.3 \%$ at the hospital level. The most common non-compliance was non-wearing of masks $(85.7 \%)$ at health centers and $53 \%$ at the hospital. Lack of social distancing was reported by $57.1 \%$ at health facility, citing limited work space as the cause. As regards action taken when there was non-compliance, it was mainly training and retraining, reinforcing measures and reminders. Overall, $75.7 \%$ reported that based on their interventions, they observed improvements in compliance. For sustained compliance to COVID-19 prevention and control standards, the nurse leaders employed continuous sensitization (hospital level 66.6\%, $57.1 \%$ at health centre level) and ensuring availability of PPEs (46.7\% at hospital level and $28.6 \%$ at health centers).

\section{Psychological Support to Nurses Providing COVID-19 Services}

Nurse leaders were asked if they offered psychological support for the safety and personal wellbeing of nurses they supervise (Table 16). They cited advocacy and counselling (63.3\%), ensuring PPEs $60 \%$ and continuous sensitization in $50 \%$ of hospital level nurse leaders. At the health centers nurse leaders mainly offered continuous sensitization and PPEs $(85.7 \%)$ and advocacy and counselling (71.3\%). Ensuring nurses had adequate rest was only reported by six leaders $(16.2 \%)$. Five $(16.7 \%)$ leaders at hospital level and only one (14.3\%) at the health center level. 


\section{Partnerships and Networking}

In terms of collaborative efforts in delivery of health services, $30(81 \%)$ of all nurse leaders indicated NGOs as collaborating partners (Table 17). Fifty-six percent (56.8\%) mentioned multi-lateral organizations, $40.5 \%$ indicated traditional leaders (15 nurses, only one was from a health center). Collaboration with faith-based organizations was reported by eight leaders $(26.6 \%)$ at hospital level and three $(42.9 \%)$ at health center level. The nurse leaders also outlined the contributions made by the collaborating partners. At hospital level, nurse leaders reported that partners participated in meetings (26\%), donation of supplies and PPEs $(23.3 \%)$. While at the health center level, nurse leaders indicated partners collaborated in community sensitization (71.4\%) and donation of PPEs (28.6\%). Only 14 leaders at hospital level named the collaborating partners while a total of $85.7 \%$ nurse leaders at health centers named the collaborating partners.

Table 7: Overall experience during COVID-19 pandemic

Overall experience in leading nursing services during COVID-19

National level Provincial level

1. COVID-19 provided new learning experience 1. Provision of quality care was compromised and emphasized need for preparedness.

2. Work was challenging even when there was a plan for nursing because nurses have no role in decision making and no power.

3. Difficulties were common when there was no teamwork and the fact that no incentives were provided resulted in lack of motivation. 4. Communication was very important for mobilizing nurses and for sensitization. 5. Technology was very useful for accessing information and sharing of information with other nurse leaders.

1. Provision of quality care was compromise
because of limited resources, inadequately trained nurses on infection control, fear of contracting COVID-19 and stigma. 2. Unpreparedness of the health system at beginning increased risk of infection to nurses due to lack of PPEs.

3. Shortage of nursing personnel to support COVID-19 patients and stress due to overwork of the few nurses

4. Limited facilities and challenges for use of IT for work and communication.

5. Good positive work relationships with partners.

6. Lack of incentives or tokens of appreciation.

7. The Incident Management System at National

Public Health Institute helped reduce anxieties and overcame some challenges.
District level

1. Lack of nursing plans, risks of infection, lack of appreciation left nurses feeling neglected which made work difficult. 2. Inadequate staff and deployment of untrained staff compromised patient care. 3. Long working hours, stress due to physical and emotional impact of COVID-19 on staff and their families was not addressed and not given priority by management at all levels.

Table 8: Strengthening partnerships and engaging nurse leaders to ensure impact in epidemic response

1 Strengthening of partnerships post-COVID-19 to support other nursing priorities

National level

1. Partners should be aware of the specific needs for COVID-19 and there should be reporting on the use of donations.

2. Partners should be encouraged to support other health areas such as capacity building. 3. Continuous engagement of partners, transparency in use of donations and when possible targeting the assistance provided.

Provincial level

integrated services).
2 Areas nursing leaders should be engaged in to have a greater impact on responding to epidemics

1. Better collaboration and improving working together with other health leaders and better involvement in decision making on COVID-19 issues.

2. Provision of logistics and resources for nurse leaders at all levels to perform their supervisory and monitoring functions. 3. A firm commitment by leadership to engage nurse leaders in planning that is currently done at a very high level.

4. Develop/ensure that at all work levels there is an environment that is collaborative and inter- disciplinary so that nurse leaders do not feel intimidated, are treated as equals and recognized for their role in management and delivery of health services.
1. Partners role to be involved in more than just

COVID-19 (other areas such as $\mathrm{MCH}$,

2. Nurse leaders should have a seat at the provincia coordination meeting so they can buy in into the issues or needs for nursing and have input in planned activities for nursing.

3. Coordination of different partners to avoid duplication of support.

4. Nurse leaders should have a good understanding of the mandates of the different partners so as to maximize their roles.

District level

1. Partners involvement in planning to avoid duplication. Task forces to include partners.

2. Improve communication and sharing of updates with the partners. 3. Provide feedback on what their support has contributed.

4. Involve them as members of the District Health Teams.

1. Capacity building of nurse leaders in the area of infection control.

2. Specific guidelines for major outbreaks should be readily available.

3. Nurse leaders should be involved in training of staff. This should not be left to people coming from the national level. Use of training of trainers (TOTs) should be given priority. 4. Nurse leaders should be involved in all areas of work including planning, be represented at key meetings and as early as possible when there are outbreaks. 5. Opportunities should exist for sharing of experiences with other nurses.
1. Nurses should be involved right from the start and provide input at all levels. 2. PPEs should be provided in full to prevent infection among nurses. 3. Nurses should be involved in all areas including planning management, resource mobilization, monitoring and evaluation. 
Table 9: Changes needed to improve the effectiveness of nurse leaders at national, provincial and district levels

\begin{tabular}{|c|c|c|}
\hline National level & Provincial level & District level \\
\hline $\begin{array}{l}\text { 1. Action plans should be in place for nursing } \\
\text { in epidemics. }\end{array}$ & $\begin{array}{l}\text { 1. Logistics (transport, communications } \\
\text { to perform essential functions. }\end{array}$ & 1. Technical support for mentorship. \\
\hline 2. Improve communications between nurse & 2. Standardized strategic plans and guidelines. & 2. Dedicated logistics for performance of their \\
\hline 3. Logistics should be made available for activities & 4. Ensure continuous professional development and & 3. Specific nursing strategic plan for COVID-19. \\
\hline such as mentoring, psychosocial support for & offer exchange programme with other provinces. & 4. Working in a multi -disciplinary team. \\
\hline personnel, transport during an epidemic & 5. Advocacy so that nurses' voices are & 5. Adequate staffing at health facilities. \\
\hline $\begin{array}{l}\text { and not rely on others. } \\
4 \text { Targeted rather than basket support for specific }\end{array}$ & heard and not looked down upon. & \\
\hline $\begin{array}{l}\text { 4. Targeted, rather than basket support for specific } \\
\text { activities related to nursing should be encouraged. }\end{array}$ & 6. Nursing plans at provincial level should be fully & \\
\hline 5. Provide more opportunities for continuous & budgeted for and provided. & \\
\hline professional development and enhance & & \\
\hline (2) & & \\
\hline $\begin{array}{l}\text { 6. Clarity on policy as well as provision of } \\
\text { incentives for working in risky environments. }\end{array}$ & & \\
\hline
\end{tabular}

Table 10: Health facility level leaders' positions and their roles in COVID-19 response

\begin{tabular}{|c|c|c|c|c|c|c|c|}
\hline & & Hospita & & Health & & Total & \\
\hline & Variable & $\mathrm{n}=30$ & $\%$ & $\mathrm{n}=7$ & $\%$ & $\mathrm{n}=37$ & $\%$ \\
\hline 1 & Position of leader & & & & & & \\
\hline & a) Registered Nurse & 1 & 3.3 & 5 & 71.4 & 6 & 16.2 \\
\hline & b) Nursing Officer & 23 & 76.6 & 1 & 14.3 & 24 & 64.9 \\
\hline & c) Provincial Nursing Officer & 2 & 6.6 & - & - & 2 & 5.4 \\
\hline & d) Chief Nursing Officer & 2 & 6.6 & - & - & 2 & 5.4 \\
\hline & e) Enrolled Nurse & - & - & 1 & 14.3 & 1 & 2.7 \\
\hline 2 & Role in COVID-19 fight & & & & & & \\
\hline & a) Infection control & 16 & 53.3 & 5 & 71.4 & 21 & 56.8 \\
\hline & b) Resource organization & 20 & 66.7 & 4 & 57.1 & 26 & 70.3 \\
\hline & c) Technical support & 6 & 16.7 & 0 & 0.0 & 6 & 16.2 \\
\hline & d) Information sharing & 9 & 30.0 & 3 & 42.9 & 12 & 32.4 \\
\hline & e) Monitor patient care & 18 & 60.0 & 1 & 14.3 & 19 & 51.4 \\
\hline & f) Detection/swabbing & - & - & 1 & 14.3 & 1 & 2.7 \\
\hline
\end{tabular}

Table 11: Key daily and routine activities and nursing leadership during COVID-19 and key characteristics for the nurse leader

\begin{tabular}{|c|c|c|c|c|c|c|c|}
\hline & \multirow[b]{2}{*}{ Variable } & \multicolumn{2}{|c|}{ Hospital } & \multicolumn{2}{|c|}{ Health Centre } & \multicolumn{2}{|l|}{ Total } \\
\hline & & $\mathrm{n}=30$ & $\%$ & $\mathrm{~N}=7$ & $\%$ & $\mathrm{~N}=37$ & $\%$ \\
\hline \multirow[t]{4}{*}{$\overline{1}$} & Key routine daily activities & & & & & & \\
\hline & a) Spot-checks & 19 & 63.3 & 3 & 42.9 & 21 & 56.8 \\
\hline & b) Check COVID-19 precautions adherence & 21 & 70.0 & 5 & 71.4 & 26 & 70.3 \\
\hline & c) Admin and management duties & 21 & 70.0 & 6 & 85.7 & 26 & 70.3 \\
\hline \multirow[t]{7}{*}{2} & Key functions of Nurse Leader & & & & & & \\
\hline & a) Strategic direction setting & 20 & 66.7 & 3 & 42.9 & 23 & 62.2 \\
\hline & b) Leading and establishing nursing structures & 24 & 80.0 & 3 & 42.9 & 27 & 73.0 \\
\hline & c) Engaging nurses in COVID-19 services & 25 & 83.3 & 5 & 71.4 & 30 & 81.1 \\
\hline & d) Developing nursing capacity & 24 & 80.0 & 4 & 57.1 & 29 & 78.4 \\
\hline & $\begin{array}{l}\text { e) Establish collaboration, networks with } \\
\text { professionals and others }\end{array}$ & 13 & 43.3 & 2 & 28.6 & 15 & 40.5 \\
\hline & $\begin{array}{l}\text { f) Advocacy and involving family, community } \\
\text { and patients in prevention/control }\end{array}$ & 22 & 73.3 & 5 & 71.4 & 27 & 73.0 \\
\hline \multirow[t]{6}{*}{3} & Key characteristics for nurse leader & & & & & & \\
\hline & a) Advocate & 12 & 40.0 & 0 & 0 & 12 & 32.4 \\
\hline & b) Educator & 18 & 60.0 & 2 & 28.6 & 20 & 54.1 \\
\hline & c) Mentor & 13 & 43.3 & 1 & 14.3 & 14 & 37.8 \\
\hline & d) Supportive & 17 & 56.7 & 1 & 14.3 & 18 & 48.6 \\
\hline & e) Empathy & 7 & 23.3 & 4 & 57.1 & 11 & 29.7 \\
\hline
\end{tabular}


Table 12: Training, competency and recognition of nurse leaders

\begin{tabular}{|c|c|c|c|c|c|c|c|}
\hline & \multirow[b]{2}{*}{ Variable } & \multicolumn{2}{|c|}{ Hospital } & \multicolumn{2}{|c|}{ Health Centre } & \multicolumn{2}{|l|}{ Total } \\
\hline & & $\mathrm{n}=30$ & $\%$ & $\mathrm{n}=7$ & $\%$ & $\mathrm{n}=37$ & $\%$ \\
\hline \multirow[t]{6}{*}{1} & $\begin{array}{l}\text { Involved in training of staff to be deployed to } \\
\text { COVID-19 quarantine centres }\end{array}$ & 10 & 33.3 & 4 & 57.1 & 14 & 37.8 . \\
\hline & a) Infection prevention & 13 & 43.3 & 4 & 57.1 & 17 & 45.9 \\
\hline & b) Case management & 13 & 43.3 & 3 & 42.9 & 16 & 43.2 \\
\hline & c) Use of PPE & 16 & 53.3 & 2 & 28.6 & 18 & 48.6 \\
\hline & d) Contact tracing & 6 & 20.0 & 2 & 28.6 & 8 & 21.6 \\
\hline & e) Waste management & 6 & 20.0 & 1 & 14.3 & 7 & 18.9 \\
\hline \multirow[t]{6}{*}{2} & Areas respondents felt competent & & & & & & \\
\hline & a) National standards for infection control. & 19 & 63.3 & 7 & 100 & 26 & 70.3 \\
\hline & b) Prevention and control of COVID-19. & 19 & 63.3 & 3 & 42.9 & 22 & 59.5 \\
\hline & c) Management of COVID-19 cases & 15 & 50.0 & 4 & 57.1 & 19 & 51.4 \\
\hline & d) Social mobilization & 14 & 46.7 & 4 & 57.1 & 18 & 48.6 \\
\hline & e) Media communication & 11 & 36.7 & 2 & 28.6 & 13 & 35.1 \\
\hline \multirow[t]{3}{*}{3} & Recognition and appreciation of nurse leaders by: & & & & & & \\
\hline & Other health professionals & 9 & 30.0 & 1 & 14.3 & 10 & 27.0 \\
\hline & The general public & 7 & 23.3 & - & - & 7 & 18.9 \\
\hline
\end{tabular}

Table 13: Role of nurse leaders in overseeing COVID-19 nursing services

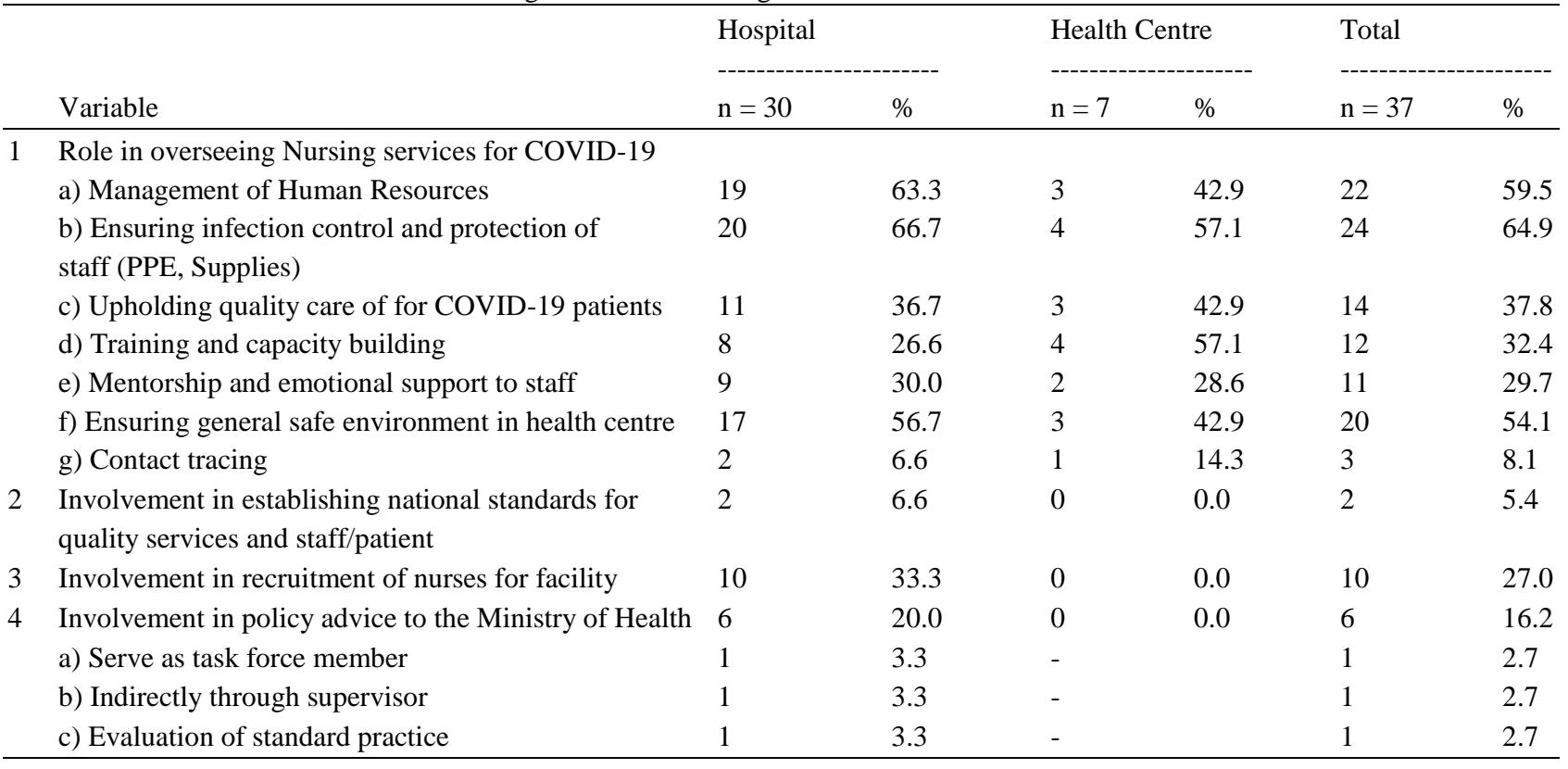

Table 14: Role of Information technology in COVID-19 service delivery

\begin{tabular}{|c|c|c|c|c|c|c|}
\hline \multirow[b]{2}{*}{ Variable } & \multicolumn{2}{|c|}{ Hospital } & \multicolumn{2}{|c|}{ Health Centre } & \multicolumn{2}{|l|}{ Total } \\
\hline & $\mathrm{n}=30$ & $\%$ & $\mathrm{n}=7$ & $\%$ & $\mathrm{~N}=37$ & $\%$ \\
\hline \multicolumn{7}{|l|}{ Use of IT in work } \\
\hline a) Communication & 14 & 46.7 & 3 & 42.9 & 17 & 45.9 \\
\hline c) Information searches & 5 & 16.7 & 2 & 28.6 & 7 & 18.9 \\
\hline d) Meetings & 8 & 26.6 & 0 & 0.0 & 8 & 21.6 \\
\hline e) Reporting & 12 & 40.0 & 4 & 57.1 & 16 & 43.2 \\
\hline
\end{tabular}


Table 15: Monitoring infection control standards

Infection control and prevention standards monitored at facility

\begin{tabular}{llllll} 
Hospitals & & \multicolumn{2}{l}{ Health centres } & \multicolumn{2}{l}{ Totals } \\
$-\mathrm{n}=30$ & $\%$ & $\mathrm{~N}=7$ & $\%$ & $\mathrm{~N}=37$ & $\%$ \\
\hline 26 & 86.7 & 4 & 57.1 & 31 & 83.8 \\
22 & 73.3 & 6 & 85.7 & 28 & 75.7 \\
13 & 43.3 & 2 & 28.6 & 15 & 40.5 \\
16 & 53.2 & 6 & 85.7 & 22 & 59.5 \\
7 & 23.3 & 0 & 0.0 & 7 & 18.9 \\
4 & 13.3 & 4 & 57.1 & 8 & 21.6 \\
1 & 3.3 & 0 & 0.0 & 1 & 2.7 \\
& & & & & \\
8 & 26.6 & 2 & 28.6 & 10 & 27.0 \\
10 & 33.3 & 3 & 42.9 & 13 & 35.1 \\
8 & 26.6 & 4 & 57.1 & 12 & 32.4
\end{tabular}

4. Ensuring compliance with infection prevention and control standards at facility
a) Hand hygiene training
b) Continuous sensitization
c) Ensure availability of PPE
d) Spot-checks
e) Provision of guidelines

$\begin{array}{llllll}8 & 26.6 & 0 & 0.0 & 8 & 21.6\end{array}$

$\begin{array}{llllll}20 & 66.6 & 4 & 57.1 & 24 & 64.9\end{array}$

$\begin{array}{llllll}14 & 46.7 & 2 & 28.6 & 16 & 43.2\end{array}$
Improvement in compliance following action

$\begin{array}{llllll}11 & 36.7 & 1 & 14.3 & 12 & 32.4\end{array}$

$\begin{array}{llllll}12 & 40.0 & 1 & 14.3 & 13 & 35.1\end{array}$
22

$73.3 \quad 6$

Table 16: Psychological support

\begin{tabular}{|c|c|c|c|c|c|c|}
\hline \multirow[b]{2}{*}{ Variable } & \multicolumn{2}{|c|}{ Hospitals } & \multicolumn{2}{|c|}{ Health Centres } & \multicolumn{2}{|l|}{ Totals } \\
\hline & $\mathrm{n}=30$ & $\%$ & $\mathrm{n}=7$ & $\%$ & $\mathrm{n}=37$ & $\%$ \\
\hline \multicolumn{7}{|l|}{ Psychological support to staff } \\
\hline a) Advocate/provide counselling & 19 & 63.3 & 5 & 71.4 & 24 & 64.9 \\
\hline b) Ensure adequate PPE & 18 & 60.0 & 6 & 85.7 & 24 & 64.9 \\
\hline c) Ensure nurses rest enough & 5 & 16.7 & 1 & 14.3 & 6 & 16.2 \\
\hline d) Continuous sensitization & 15 & 50.0 & 6 & 85.7 & 21 & 56.8 \\
\hline
\end{tabular}

Table 17: Collaboration with partners and their contributions

\begin{tabular}{|c|c|c|c|c|c|c|c|}
\hline & \multirow[b]{2}{*}{ Variable } & \multicolumn{2}{|c|}{ Hospitals } & \multicolumn{2}{|c|}{ Health Centres } & \multicolumn{2}{|l|}{ Totals } \\
\hline & & $\mathrm{n}=30$ & $\%$ & $\mathrm{n}=7$ & $\%$ & $\mathrm{n}=37$ & $\%$ \\
\hline \multirow[t]{5}{*}{$\overline{1 .}$} & Collaborating partners on COVID-19 & & & & & & \\
\hline & a) NGOs & 25 & 83.3 & 5 & 71.4 & 30 & 81.1 \\
\hline & b) Multi-lateral agencies & 19 & 63.3 & 2 & 28.6 & 21 & 56.8 \\
\hline & c) Traditional healers & 14 & 46.7 & 1 & 14.3 & 15 & 40.5 \\
\hline & d) Faith based organizations & 8 & 26.6 & 3 & 42.9 & 11 & 29.7 \\
\hline \multirow[t]{6}{*}{2.} & Contribution of collaborating partners & & & & & & \\
\hline & a) Indirectly through $\mathrm{MOH} / \mathrm{PMO} / \mathrm{DHO}$ & 4 & 13.3 & 0 & 0.0 & 4 & 10.8 \\
\hline & b) Donate supplies and PPE & 7 & 23.3 & 2 & 28.6 & 9 & 24.3 \\
\hline & c) regular participation in meetings & 8 & 26.6 & 0 & 0.0 & 8 & 21.6 \\
\hline & d) Support personnel with food, & 2 & 6.3 & 0 & 0.0 & 2 & 5.4 \\
\hline & e) Community sensitization & 3 & 3.3 & 5 & 71.4 & 8 & 21.6 \\
\hline \multirow[t]{4}{*}{3.} & Number of named collaborating partners & 14 & 46.6 & 6 & 85.7 & 20 & 54.1 \\
\hline & a) Serve as task force member & 1 & 3.3 & - & & 1 & 2.7 \\
\hline & b) Indirectly through supervisor & 1 & 3.3 & - & & 1 & 2.7 \\
\hline & c) Evaluation of standard practice & 1 & 3.3 & - & & 1 & 2.7 \\
\hline 4. & Leaders knowing contributions from faith based organizations & 22 & 73.3 & 6 & 85.7 & 28 & 75.7 \\
\hline
\end{tabular}




\section{Challenges and Opportunities}

The nurse leaders at hospital and health center facilities were asked to outline the challenges and opportunities that resulted from the work on COVID-19. Their responses were grouped into capacity building, competencies, teamwork and networking, community engagement, infrastructure (Table 18). Research, service delivery and the nursing workforce are presented in (Table 19).

\section{Capacity Building}

Nurse leaders, especially at the health care facilities, appreciated the training and orientation, offered by NGOs and the Ministry of Health. In addition, some nurse leaders seized the opportunity to be engaged in online training programs on COVID-19. Most felt that they acquired new knowledge about the disease, its spread and response, but also noted that, it would have been better and appropriate if the nurse leaders at the health facilities or representatives had some input into the development of the training materials and strategies for training at an early stage. Some nurse leaders perceived that their frequent contact with their subordinates in COVID-19 operational sites enhanced mentorship and contributed to increased competency, motivation and improved the quality of services. The specific competences that were improved included; infection prevention and control measures, critical nursing care and epidemic preparedness and response. Furthermore, the nurse leaders stated that leadership (especially change management), lobbying, communication and technology use are important for continuous professional development.

\section{Teamwork and Networking}

The nurse leaders stated that there was visibility of nursing leadership during the COVID-19 pandemic as the disease raised awareness amongst the health professionals. They collaborated with other teams and ensured timely reporting of health data from health facilities and up the health system ladder. There was enhanced and broadened partnerships among organizations that support health facilities. Some NGOs provided the critical materials and supplies for COVID-19 prevention and control, while others engaged in and supported continuous professional development. The nurse leaders noted that the nature of COVID-19, which required a concerted effort, demonstrated the indispensability of the role of multidisciplinary teams in service delivery, from health promotion, prevention, management and care to follow-up. The COVID-19 pandemic essentially brought nursing leadership closer to nurses in service areas and strengthened intra and interprofessional collaboration both in training/orientations and service delivery.

\section{Community Engagement}

Nurse leaders noted that the participation of communities in implementing policy change was an opportunity not to miss as most people saw the danger COVID-19 posed. This response can be attributed to the enhanced and sustained community health-seeking behaviors that were observed in some locations. However, the strategy of "lockdowns" also affected the delivery of key messages to households.

\section{Research}

There was a substantial voice among nurse leaders on the issue of research, in particular, the inability to participate in COVID-19 related research mainly due to the intensity of work. This was based on the recognition of the importance of delivering nursing services that are evidence-based. They acknowledged that research is an important aspect of nursing services that requires much more focus in the future to ensure that evidence derived from nursing research is put into practice.

\section{Infrastructure}

According to the nurse leaders' experience, there was concern regarding the lack of facilities for nurses and other health workers at the start of the epidemic. Some of these were related to the infrastructure for social distancing in work spaces, sanitary facilities including showers and changing rooms for staff at the end of their shifts to minimize the possibility of transmitting the infections to their families. Also noted were COVID-19 facilities that had multiple entry and exit points compromising the effectiveness of traffic control.

\section{Service Delivery}

The nurse leaders at the health facilities overwhelmingly noted major improvement in response addressing issues related to infection control, human resource needs and supplies for nursing care of patients due to consistency in ensuring support for adhering to infection prevention and patient care. As regards non-compliance to universal precautions and proper use of PPEs, the leaders noted that this could have been attributed to work overload, shortage of staff and insufficient supervision and mentoring capacity. This increased the risk of acquiring and spreading COVID-19. The nurse leaders however stated that at times, the facilities experienced erratic supplies of PPEs (which at times were not the correct sizes) and medical and surgical supplies. This compromised service delivery because the nursing staff had to improvise so as to minimize the risk of infection spread among themselves and the patients. Furthermore, the nurse leaders indicated that in cases where nurses were infected with COVID-19, the support and care they received was not adequate because specific guidelines to deal with occupational exposure and infection were not available. The leaders shared their experience in relation to testing of suspected cases of COVID-19 patients admitted to the health facilities. At the beginning of the outbreak, there 
were major delays in receiving COVID-19 test results. The leaders stated that this was a major constraint for early nursing planning as well as infection risk reduction among health workers. Lastly, it was also reported by nurse leaders at hospital and health centers that, there was so much focus on making sure there were adequate supplies for the COVID-19 response, neglecting the provision of supplies for patients with other health conditions.

\section{Quotes from Nurse Leaders on Service Delivery Experiences}

"We need more nurses trained in critical care nursing with focus on respiratory care". "Due to the delay of results (COVID-19 tests results), clients were getting upset with the nurses. Nurse leaders had to call responsible people for results".

\section{Nursing Workforce}

Nurse leaders noted that the late involvement of nursing leadership in policy development and programme planning led to inadequacy in the early preparation and implementation of services at the frontline. Their subsequent involvement in staff placement, redeployment, encouragement and reassurance was a big part of ensuring services were delivered accordingly. However, the leaders stated that the initial group of nurses that were deployed did not have the full competencies for addressing COVID-19 patient care needs. This led to insecurities in confidence in performing their tasks. Nurse leaders attributed this to the late involvement in the training of nurses on COVID-19.
The nurse leaders further indicated that the chronic shortage of the nursing workforce hindered the optimal deployment of nurses to work on COVID-19, especially for the care of the critically ill patients needing oxygen. Nurses were more affected by the risk of infection across the structure including nurse leaders who undertook clinical work in support of the understaffed nurses. COVID-19 infections and fear among the nursing workforce due to inadequate PPEs hindered the smooth deployment of staff to COVID-19 service delivery sites. The nurse leaders recognized that the COVID-19 pandemic offered an opportunity to engage nurses who had retired or were not in service to participate in the response. The difficulty in work scheduling and assigning of duties due to shortage of staff resulted in psychological and physical strain among the available staff.

\section{Nurse Leaders Quotes on Managing the Workforce and their Work}

"...we feared nurses dying especially when we did not have full PPEs"

"...it was overwhelmingly stressful due to long working late hours in the evening and then early in the morning one had to do the report. So I slept very little in order to do reports for submission in the morning."

“... nurses worked $6 \mathrm{~h}$ nonstop with only 2 nurses taking care of critically ill patients. I used to work up to 3 am preparing reports". "...because of long working hours, we started giving ourselves two-day breaks. In the end some got sick, e.g., with high blood pressure"

Table 18: Challenges and opportunities in capacity building, teamwork, community engagement and infrastructure cited by nurse leaders at health facilities

\begin{tabular}{|c|c|c|}
\hline & Challenges & Opportunities \\
\hline Capacity building & $\begin{array}{l}\text { Late involvement in the training on COVID-19 } \\
\text { making the deployed nurses insecure of their } \\
\text { competencies and capabilities. }\end{array}$ & $\begin{array}{l}\text { Utilization of online training programmes on } \\
\text { COVID-19 disease, transmission, management } \\
\text { and control. } \\
\text { Increased knowledge on outbreak } \\
\text { and emergency response. } \\
\text { Availability of orientation/training offered } \\
\text { by Ministry of Health and NGOs. } \\
\text { Enhanced and regular mentorship of nurses } \\
\text { working in COVID-19 related service areas. } \\
\text { Potential of developing well targeted continuous } \\
\text { professional development programmes. }\end{array}$ \\
\hline Competencies & Skills limitation in critical care such as intubation. & $\begin{array}{l}\text { Improvement of skills in critical care nursing, } \\
\text { disaster preparedness and response, leadership } \\
\text { (change management), lobbying/communication, } \\
\text { infection prevention and control measures and } \\
\text { technology use. }\end{array}$ \\
\hline Teamwork and Networking & & $\begin{array}{l}\text { Systems awareness of the importance of } \\
\text { teamwork, broadened partnerships and } \\
\text { enhanced links with organizations } \\
\text { that support health facilities. }\end{array}$ \\
\hline
\end{tabular}


Table 18: Continue

Community engagement

Research

Infrastructure
"Lockdown" affected delivery of key messages to households.

Inability to participate in COVID-19 related research due to the intensity of work. Infrastructure limitations affected the implementation of social distancing policy. Multiple entry and exits rendered traffic control difficult in health facilities. Lack of appropriate sanitary facilities (e.g., staff shower rooms) affected motivation of staff in COVID-19 centres.
Nursing leadership being closer to nurses in service areas for mentorship and support. Broadening of experience exchanged among various health facilities. Engagement of NGOs in CPD activities. Indispensable role of multidisciplinary teams in service delivery (health promotion, prevention, care).

Participation of the community in implementing policy change.

Sustainment of health-seeking behaviour. Participation in operational research. Introduction of evidence-based practice.

Table 19: Challenges and opportunities in service delivery and nurse workforce cited by nurse leaders at health facilities

\begin{tabular}{|c|c|c|}
\hline & Challenges & Opportunities \\
\hline Service delivery & $\begin{array}{l}\text { Erratic supplies of PPEs and other medical } \\
\text { and surgical materials compromised service } \\
\text { delivery resulting in nurses having to improvise. } \\
\text { Provision of befitting care to nurses infected } \\
\text { with COVID-19 due to inadequate infrastructure. } \\
\text { Focus and provision of supplies on COVID-19 } \\
\text { patients at the expense of patients with other } \\
\text { health conditions. } \\
\text { Compliance to universal precautions and PPEs was } \\
\text { not } 100 \% \text { adding to the already overwhelmed tasks } \\
\text { of nurse leaders on mentoring and capacity building. } \\
\text { Inability to offer optimal safe working environment } \\
\text { due to shortage of staff and inconsistent and } \\
\text { inadequate supplies making it difficult to reduce } \\
\text { staff exposure to COVID-19. }\end{array}$ & $\begin{array}{l}\text { Improvement in emergency response. } \\
\text { Awareness on infection prevention, practices, } \\
\text { care and programme management. } \\
\text { Innovation in times of scarce PPEs. } \\
\text { Consistency in grant approvals to ensure } \\
\text { availability of medical non- medical supplies } \\
\text { and materials. } \\
\text { Recognition of the importance of adherence to } \\
\text { universal precautions and PPEs. } \\
\text { Recruitment of a higher number of nurse } \\
\text { leaders to improve quality of work through } \\
\text { mentorship. }\end{array}$ \\
\hline Nursing workforce & $\begin{array}{l}\text { Late involvement of nursing leadership in programme } \\
\text { planning and policy development leading to lack of } \\
\text { early preparedness of frontline workers. } \\
\text { Shortage of nursing workforce hindered the } \\
\text { optimal deployment of nurses to work on COVID-19. } \\
\text { Inadequate staff to take care of critically ill } \\
\text { patients needing oxygen. } \\
\text { Difficulty in convincing the nursing workforce to } \\
\text { work on COVID-19 given its high infectivity. } \\
\text { Delay in receiving COVID-19 results compounded } \\
\text { by the shortage of testing kits had negative implications } \\
\text { in the early nursing planning and interventions. } \\
\text { Nurses were more affected by risk of infections across } \\
\text { the structure as nurse leaders undertake clinical work } \\
\text { in support of the understaffed nurses. } \\
\text { COVID-19 infections among staff working in COVID-19 } \\
\text { delivery sites hindered the smooth deployment of staff. Stigma } \\
\text { and fear of contracting COVID-19 brought about psychological } \\
\text { trauma among nurses which consequently led to high attrition } \\
\text { of the nursing workforce. } \\
\text { Difficulty in work scheduling and assigning of duties due to } \\
\text { shortage of staff resulting in psychological and physical strain o }\end{array}$ & $\begin{array}{l}\text { Employment of nurses not in services due to } \\
\text { need for staff surge. } \\
\text { Recognition of importance of staff } \\
\text { placement/deployment, motivation, } \\
\text { encouragement and reassurance in the } \\
\text { nursing in a health risk area. } \\
\text { Making improvements in staff well-being. } \\
\text { Visibility of the importance of nursing } \\
\text { leadership and management in the } \\
\text { effectiveness/efficiency of service delivery. } \\
\text { Strengthening nursing leadership and reporting } \\
\text { of health systems data. } \\
\text { Potential for establishing a well resourced } \\
\text { physiological support systems for nurses and as } \\
\text { the "carers of carers". }\end{array}$ \\
\hline
\end{tabular}




\section{Discussion}

This study identified the key nursing leadership elements at national, provincial and district levels as well as at the health care facility levels that were key in the contribution of nursing leadership to the challenges posed by the COVID-19 pandemic and opportunities that would enhance and strengthen nursing leadership in future pandemics in Zambia. Being prepared for pandemics requires a firm commitment by higher level management to engage nurse leaders in planning and not only in implementation. The finding in this study that planning for the COVID-19 response was done at a very high level in the Ministry of Health and nurse leaders were involved only at the review stage is of concern. The nursing leadership felt that it was one of the reasons for some of the inadequacies noted in the early preparation and implementation of services at the frontline. Even when plans were subsequently available, some of the activities had no dedicated budget. Nurse leaders in Zambia desired to be involved right from the start in order to provide input at all levels and in all areas of management that affect nursing care and the nursing workforce. It is therefore not surprising that, only one $(20.0 \%)$ of the national level nurse leaders mentioned planning, budgeting and implementation as a main responsibility. Similar research shows that widespread education and training of nurses about policy has not yet been realized. Moving nurses from being recipients and implementers of health policy decisions, to being leaders with a strong voice in the development or reform of policy will take a concerted strategic effort (Turale and Kunaviktikul, 2019).

The finding that most nurse leaders were not in confirmed job positions hindered their ability to advocate for appropriate deployment of nursing staff to support the response to COVID-19. The lack of commitment in the health system to involve nurses in, for example planning, should be urgently addressed. Visibility and involvement are of great importance for the nursing leadership and can improve the management, effectiveness and efficiency of service delivery while managing the high expectations demanded of them by the nursing workforce and the people they serve. Addressing this issue is critical to maintaining the motivation of nurse leaders.

Standardized nursing strategic or operational plans and guidelines for pandemics are essential for the delivery of effective services and should be fully budgeted for and funded. Fully funded plans for emergencies would ensure availability of PPEs and other logistical resources such as transport and communication which nurse leaders in this study mostly lacked. A recent study has shown that nurses who did not consider the quantity and quality of PPEs as adequate presented significantly higher levels of depression, anxiety and stress (Sampaio et al., 2020). These aspects are important for supervisory and monitoring functions and the creation of an optimal safe work environment. Nurse leaders narrated that, the focus given to supplies for effective management of COVID-19 cases, infection prevention, control and protection of the health staff (PPE) though appropriate, was sometimes at the neglect of key supplies for other health conditions. This is clearly a management issue that requires a comprehensive approach whenever there are epidemics.

Part of being an effective nurse leader is to be inspirational to nurses and to motivate them to work even in difficult times. Lack of clarity on incentives was a demotivating factor for nurses to work in COVID-19 wards and quarantine centres. In addition, the increased risk of COVID-19 infections among staff in the early days of the pandemic hindered deployment of staff to these sites. The study also revealed that facilities for use by the nursing staff working in COVID-19 wards and quarantine centres were inadequate or non-existent. Furthermore, provision of befitting care to nurses infected with COVID-19 was not optimal due to inadequate infrastructure. Appropriate infrastructure together with incentives should be addressed and incorporated in the nursing strategic plan for epidemics.

Nurse leaders and frontline nurses working on COVID-19 experienced stigma and fear of contracting the disease. This brought about psychological trauma among nurses which consequently led to high attrition of the nursing workforce. It is worth noting that, although nurses are dedicated to providing care and do not regret working in the nursing profession, they still seek support for their needs and ethical concerns (Sperling, 2021).

This study confirmed the effects of shortage of nursing staff on COVID-19 service delivery. Inadequate staff and deployment of inexperienced staff or staff with limited experience in infectious disease, patient care or critical care compromised care of COVID-19 patients. Long working hours, stress due to the physical and emotional impact of COVID-19 on staff and their families, aggravated by shortage of staff was not addressed and not given priority by management at all levels. Having in place an operational plan based on patient load, work hours and critical patient admissions would alleviate this situation (Zhang et al., 2021). The finding that $60 \%$ of nurse leaders were not aware of a specific policy on what to do when a health care worker is infected points to the importance of establishing a well-resourced support system for nurses as carers (of ordinary patients) and as "carers of carers" (of nurses as patients) before, during and after pandemics. According to the International Council of Nurses survey, 20\% of National Nurses Associations (NNAs) reported an increased rate of nurses leaving the profession in 2020. Additionally, $90 \%$ of the NNAs were concerned that the pandemic is driving increased numbers of nurses to leave, or reporting an intention to leave the profession once the pandemic is over (ICN, 2021). In this study, it was reported that in 
situations where nurses were exposed to suspected cases of COVID-19, the delay in receiving COVID-19 test results had implications for planning and interventions to ensure an optimal safe work environment. Priority should be given to ensuring early COVID-19 results especially in nonCOVID-19 management facilities. Addressing the physical and psychological needs of nursing staff during pandemics is important for motivation, encouragement and reassurance of the nursing staff working in health risk areas in the context of occupational health and safety. Systemic support, adequate knowledge and resilience have been identified as factors protecting against adverse mental health outcomes amongst health workers during the COVID-19 pandemic (De Kock et al., 2021). Enhanced knowledge and skills amongst nurse leaders would have resulted in better support, mentorship and supervision as well as an opportunity for sharing of experiences with other nurses serving in COVID-19 service delivery sites in the country.

Another finding in this study was that nurse leaders at provincial, district and health facilities did not fully utilize ICT mainly due to lack of capacity and infrastructure, such as, poor or no internet connection. ICT has been shown to play a key role in the performance of nursing leadership roles. Information and communication technologies are becoming an impetus for quality health care delivery by nurses. The use of ICTs by nurses can impact their practice, modify the ways in which they plan, provide, document and review clinical care (Rouleau et al., 2017). Policies that support an increased structure for effective communication across levels allow nurse leaders the ability to foster a sense of care and concern for nurses and mitigate issues as they arise (Simonovich, et al., 2021).

Capacity building activities during the COVID-19 response were comprehensive. However, since they were not integrated into an existing overall Continuous Professional Development (CPD) plan, the long- term impact in addressing future pandemics is questionable. The frequent contact among nurse leaders and their subordinates necessitated by COVID-19 resulted in improved competencies. This reflects the positive impact of regular supportive supervision and should be considered a best practice. To improve their competencies, a more well-planned and organized CPD programme should be instituted and lessons learnt from the current COVID-19 outbreak should be incorporated in the training, with direct involvement of nurse leaders. An effective way to ensure long-term sustainability of the CPD programme could be collaboration with established academic institutions of higher learning. An example of this is what was done in the Caribbean, where the University of West Indies School of Nursing, a Pan American Health Organization/World Health Organization Collaborating Centre for Nursing and Midwifery, developed a course to equip nurses with the right skills and competencies to provide critical nursing care in intensive care units. This four-week training was a combination of virtual sessions with face-to-face training in a clinical setting. The course covered; clinical care for COVID-19 patients, foundations of critical care, management of respiratory conditions, renal dysfunction and replacement theory, epidemiology and infection control, management of neurological conditions and the Critical Care Practicum (PAHO, 2021). Such a programme can contribute highly to infectious disease epidemic or pandemic preparedness and could be expanded to include other aspects of nursing. The finding that nurse leaders at hospital and health centre levels considered the important leadership characteristics to be, as educators and supportive supervisors, calls for the need to build capacity amongst them to take on mentorship and serve as advocates for nursing personnel under their supervision. This could be included as a priority in a CPD programme. Some of the competency areas the nurse leaders identified for inclusion in a CPD programme were; critical care nursing, disaster preparedness and response and leadership (change management, critical thinking, lobbying or communication, infection prevention and control measures). Recent studies also suggest that national authorities should at their own expense train more nurses in intensive care unit (ICU) skills who could be deployed when the needs arise (Isobe et al., 2020).

Nurse leaders at all levels in this study appreciated the inter-disciplinary working environments during the COVID-19 response. However, in most settings, it did not provide an opportunity to remove feelings of intimidation nor did it promote equality and recognition of their key roles in the delivery of health services. Unfortunately, some studies show nurse leaders are still confined within their nursing orbit (Pakhide and Verma, 2021). COVID-19 however, offers an opportunity for nurse leaders in Zambia to be visible and articulate their roles to ensure their voices are heard. Furthermore, partnerships at all levels were recognized for playing a critical role in the COVID-19 pandemic response. Although partners' focus was on donation of medical supplies and PPEs, which was appropriate, their role can be broadened to support other health initiatives and capacity building activities for nursing. This can be achieved by their involvement through ongoing participation in fora such as health coordination committees and task forces for specific initiatives. This would improve coordination, avoid duplication of support and provide an opportunity for nurse leaders to understand the mandates of the local partners. A key to effective partnerships is the requirement for transparency and reporting on use of donations.

Lastly, research is critical for evidence-based nursing practice. Realistically, due to intensity of work on COVID19 , it was difficult for nurse leaders to initiate operational research. Nevertheless, during their work on COVID-19, nurses should identify areas where operational research would lead to improved nursing services. Evidence-based 
practice would strengthen the nursing leadership in reporting of health systems data as well as contribute to innovative practice, which is uniquely Zambian. This requires funding (Allobaney et al., 2020). Some of the areas that can be prioritized include, stress and psychological factors due to the COVID-19 pandemic among health personnel and innovative nursing care practices.

\section{Conclusion}

This study identified a broad range of interventions that require attention. Immediate priority for future disease outbreaks of epidemic potential and nursing should be given to early nurse leadership involvement in policy development, operational nursing planning for epidemics, well-being of the nursing professionals, continuous professional development, information communication technology uses and operational research. The country needs to establish an effective mechanism to engage nursing leadership in the pandemic policy development as it relates to the health workforce so as to ensure that the plans address key aspects of nursing services. This would then feed into a pandemic operational plan that can be adapted to any emerging disease outbreak of epidemic potential. This operational plan would require full funding so that all critical activities are implemented in a timely manner. Drawing on lessons learnt from the COVID-19 experiences from this study, such an operational nursing plan can help cultivate exceptional nursing service, thereby promote and create safe work environments, maintain competency among nurses, support the well-being of nurses and safeguard the delivery of quality nursing services. This study also confirms the need for critical investments in infrastructure for addressing the stress and anxieties related to potential risks to nurses, in acquiring and spreading disease to their families due to inadequate facilities to maintain hygiene, compounded with long working hours and work overload. Furthermore, priority should be given to providing a wellstructured psychological support system for nurses and other health care workers for timely access to services as well as, time and space for staff to use the services whenever needed. Nurse leaders in this study noted that critical to the response to COVID-19, was the assurance of the deployment of competent nurses on the frontline. This could be achieved through continuous professional development. For such a programme to be effective, nurse leaders should have input in the development of training materials and strategies for training at an early stage. The nature and scope of nursing services requires an ongoing continuous and dynamic institutionalized professional development programme that addresses training needs of the nursing leadership and nurses on the frontlines. Information and communication technology was shown to be crucial during the COVID-19 pandemic and greatly supported the execution of nursing leader's functions. A clear cost-effective operational ICT plan which specifies types of communication and related appropriate internet platforms is required for all levels of the health care delivery system. Finally, the importance of research and its contribution to evidence based practice was recognized by nurse leaders. To create the momentum for research in nursing in Zambia, the nurse leaders should outline specific research activities, starting with the generation of research topics based on local experiences and lessons drawn from COVID-19 pandemic. Experience has shown that one of the most effective ways is having strong links with well-established higher education institutions within the country.

\section{Study Limitations}

The study was conducted between $1^{\text {st }}$ November 2020 and 20 February 2021. The study reflects the experiences of nurse leaders during the first 9 months of the pandemic. In addition, private health facilities were not included in the study. Therefore, future research which includes data beyond the first nine months of the pandemic and is inclusive of private health facilities is required. This would provide further insights into the experiences of nurse leaders during the COVID-19 pandemic.

\section{Acknowledgement}

The participation of the nurse leaders in this study during a pandemic is greatly appreciated.

\section{Funding}

This was a self-funded research by the first author borne out of the passion to contribute to the body of knowledge on nursing leadership capacity during the COVID-19 epidemic in the country.

\section{Author Contributions}

Annette Mwansa Nkowane: Generated the study concept, design, was fully engaged in data collection, analysis, drafting and preparation of the manuscript, revisions and submission for publication.

Lonia Mwape: Reviewed the draft research proposal, guided the research protocol approvals, contributed to the drafting, preparation and review of this manuscript.

Peggy S. Chibuye: Contributed to preparation and review of the draft research proposal and data collection.

Clara Tembo: Reviewed the research proposal and supported data collection.

All authors have reviewed and approved this manuscript. 


\section{Ethical Approvals}

Participation in the study was voluntary and was ascertained through a signed consent form. Participants were also provided with additional information which outlined the purpose of the study, procedures, confidentiality, risks and benefits, choice and communication of results. The study was approved by the Levy Mwanawasa Medical University Research Ethics Committee (LMMU-REC), while permission to conduct the study was granted by the National Health Research Authority (NHRA).

\section{References}

Allobaney, N. F., Nashwan, A. J., \& Mohamed, A. S. (2020). Nursing Research during COVID-19 Pandemic: A Scoping Review. Open Journal of Nursing, 10(10), 952-959. doi.org/10.4236/ojn.2020.1010066

Alrwaihi, S., Kehyayan, V., \& Johnson, J. M. (2018). Interdisciplinary shared governance: A literature. Journal of Nursing Education and Practice, 8(4). doi.org/10.5430/JNEP.V8N4P43

Butler, S., \& Diaz, C. (2017). Nurses as intermediaries in the promotion of community health: Exploring their roles and challenges. Building Healthy Neighborhoods Series, 1-25.

https://www.brookings.edu/wp-

content/uploads/2017/09/es_20170921_nurses_as_in termediaries.pdf

Chen, C. S., Wu, H. Y., Yang, P., \& Yen, C. F. (2005). Psychological distress of nurses in Taiwan who worked during the outbreak of SARS. Psychiatric Services, 56(1), 76-79. doi.org/10.1176/appi.ps.56.1.76

Cook, T. M. (2020). Personal protective equipment during the coronavirus disease (COVID) 2019 pandemic-a narrative review. Anaesthesia, 75(7), 920-927. doi.org/10.1111/anae.15071

Corless, I. B., Nardi, D., Milstead, J. A., Larson, E., Nokes, K. M., Orsega, S., ... \& Woith, W. (2018). Expanding nursing's role in responding to global pandemics 5/14/2018. Nursing outlook, 66(4), 412-415. doi.org/10.1016/j.outlook.2018.06.003

Coster, S., Watkins, M., \& Norman, I. J. (2018). What is the impact of professional nursing on patients' outcomes globally? An overview of research evidence. International journal of nursing studies, 78, 76-83. doi.org/10.1016/j.ijnurstu.2017.10.009

Curtis, E. A., de Vries, J., \& Sheerin, F. K. (2011). Developing leadership in nursing: Exploring core factors. British Journal of Nursing, 20(5), 306-309. doi.org/10.12968/bjon.2011.20.5.306

Cucinotta, D., \& Vanelli, M. (2020). WHO declares COVID-19 a pandemic. Acta Bio Medica: Atenei Parmensis, 91(1), 157.

https://www.ncbi.nlm.nih.gov/pmc/articles/PMC756 9573/
De Kock, J. H., Latham, H. A., Leslie, S. J., Grindle, M., Munoz, S. A., Ellis, L., ... \& O’Malley, C. M. (2021). A rapid review of the impact of COVID-19 on the mental health of healthcare workers: Implications for supporting psychological well-being. BMC Public Health, 21(1), 1-18. doi.org/10.1186/s12889-020-10070-3

Dran, J. (2018). A unique institutional response to the Zika virus epidemic. Obstetrics \& Gynecology, 131(4), 666-670. doi.org/10.1097/aog.0000000000002532

Fast, S. M., Mekaru, S., Brownstein, J. S., Postlethwaite, T. A., \& Markuzon, N. (2015). The role of social mobilization in controlling Ebola virus in Lofa County, Liberia. PLoS currents, 7. doi.org/10.1371/currents.outbreaks.c3576278c66b2 $2 \mathrm{ab} 54 \mathrm{a} 25 \mathrm{e} 122 \mathrm{fcdbec} 1$

Fraher, E., Spetz, J., \& Naylor, M. D. (2015). Nursing in a transformed health care system: New roles, new rules. https://repository.upenn.edu/ldi_researchbriefs/5/

Guldbrandsson, K., \& Bremberg, S. (2020). Crosssectoral cooperation at the ministerial level in three Nordic countries-With a focus on health inequalities. Social Science \& Medicine, 256, 112999. doi.org/10.1016/j.socscimed.2020.112999

Gupta, R. (2011). Enhancing community partnerships during a public health emergency: The schoollocated vaccination clinics model in Kanawha County, WV during the 2009 influenza A (H1N1) pandemic. West Virginia Medical Journal, 107(6), 28-35. https://pubmed.ncbi.nlm.nih.gov/22235709/

Haakonde, T., Musanje, F., \& Chishimba, K. (2018). Assessment of Factors Affecting the Implementation of the Integrated Disease Surveillance and Response in Public Health Care Facilities - The Case of Rufunsa District, Zambia. Diversity and Equality in Health and Care, $\quad$ 15(1), 15-22.

https://scholar.google.com/citations?view_op=view _citation\&hl=en\&user=IAAAPcwAAAAJ\&citation _for_view=IAAAPcwAAAAJ:u5HHmVD_uO8C

Isobe, T., Kunie, K., Takemura, Y., Takehara, K., Ichikawa, N., \& Ikeda, M. (2020). Frontline nurse managers' visions for their units: A qualitative study. Journal of Nursing Management, 28(5), 1053-1061. https://onlinelibrary.wiley.com/doi/full/10.1111/jon m. 13050

ICN. (2021). The Global Nursing shortage and Nurse Retention. ICN Policy Brief_Nurse Shortage and Retention. Pdf.

https://www.icn.ch/system/files/202107/ICN\%20Policy\%20Brief_Nurse\%20Shortage\%2 0and\%20Retention.pdf

Jones, K. E., Patel, N. G., Levy, M. A., Storeygard, A., Balk, D., Gittleman, J. L., \& Daszak, P. (2008). Global trends in emerging infectious diseases. Nature, 451(7181), 990-993. doi.org/10.1038/nature06536 
Jones, V., Johnson, A., Collins, M., Galiatsatos, P., Bryan, J., Krenn, S., ... \& Wilson, A. (2020). " How Long Will Covid-19 Last?" And Other Questions Youth Ask Physicians about COVID-19. Health Behavior and Policy Review, 7(4), 342-346. doi.org/10.14485/HBPR.7.4.7

Jones-Konneh, T. E. C., Murakami, A., Sasaki, H., \& Egawa, S. (2017). Intensive education of health care workers improves the outcome of Ebola virus disease: Lessons learned from the 2014 outbreak in Sierra Leone. The Tohoku journal of experimental medicine, 243(2), 101-105. doi.org/10.1620/tjem.243.101

Kim, Y. (2018). Nurses' experiences of care for patients with Middle East respiratory syndrome-coronavirus in South Korea. American journal of infection control, 46(7), 781-787. doi.org/10.1016/j.ajic.2018.01.012

Kollie, E. S., Winslow, B. J., Pothier, P., \& Gaede, D. (2017). Deciding to work during the Ebola outbreak: The voices and experiences of nurses and midwives in Liberia. International journal of Africa nursing sciences, 7, 75-81.

doi.org/10.1016/j.ijans.2017.09.002

Kren, S, (2020). Social distancing during a pandemic saves lives. John Hopkins Centre for Communication Programs.

https://ccp.jhu.edu/2020/03/17/communicating-aboutcoronavirus/

Leary, E. (2017). The Ebola Experience: Media Lessons For Nurse Leaders. https://elischolar.library.yale.edu/ysndt/1069/

Lee, J., \& Kang, S. J. (2020). Factors influencing nurses' intention to care for patients with emerging infectious diseases: Application of the theory of planned behavior. Nursing \& health sciences, 22(1), 82-90. https://doi.org/10.1111/nhs.12652

Luwabetwa, M., Banda, P., Palale, M., \& ChamaChiliba, C. (2017). A case study on the role of an essential health benefit in the delivery of integrated health services in Zambia. Regional Network for Equity in Health in East and Southern Africa.: Discussion Paper. No.111

https://www.equinetafrica.org/sites/default/files/uplo ads/documents/EHB\%20Zambia\%20Case\%20study $\% 20$ Report\%20August\%202017pv.pdf

Maben, J., \& Bridges, J. (2020). Covid-19: Supporting nurses' psychological and mental health. Journal of clinical nursing. doi.org/10.1111/jocn.15307

Mandyata, C. B., Olowski, L. K., \& Mutale, W. (2017). Challenges of implementing the integrated disease surveillance and response strategy in Zambia: A health worker perspective. BMC public health, 17(1), 1-12. doi.org/10.1186/s12889-017-4791-9
Marston, C., Renedo, A., \& Miles, S. (2020). Community participation is crucial in a pandemic. The Lancet, 395(10238), 1676-1678. doi.org/10.1016/S0140-6736(20)31054-0

MOH and ZNPHI (2020-2021). Coronavirus Disease 2019 (COVID-19). Situation reports. Sitreps. http://znphi.co.zm/news/situation-reports-newcoronavirus-covid-19-sitreps/

MOH and ZNPHI (2021). Coronavirus Disease 2019 (COVID-19). Situation reports. Sitreps. http://znphi.co.zm/news/situation-reports-newcoronavirus-covid-19-sitreps/

MOH and ZNPHI. (2020). Zambia COVID-19 response, No. 3: Risk Communication \& Community Engagement (RCCE) sub-committee - Social listening report, Ministry of Health and Zambia National Institute of Public Health. 17-23 April 2020.

Morris, F. (2012). Assessment and accreditation system improves patient safety. Nursing Management, 19(7). doi.org/10.7748/nm2012.11.19.7.29.c9374

Mulenga, L. B., Hines, J. Z., Fwoloshi, S., Chirwa, L., Siwingwa, M., Yingst, S., ... \& Malama, K. (2021). Prevalence of SARS-CoV-2 in six districts in Zambia in July, 2020: A cross-sectional cluster sample survey. The Lancet Global Health, 9(6), e773-e781. doi.org/10.1016/S2214-109X(21)00053-X

Nightingale College (2020). Nursing during Coronavirus. Salt Lake City UT Nightingale College; 2020. Nursing in COVID-19 Pandemic Times. How Can a BSN Training Help Nurses Handle The U.S. Coronavirus Health Emergency? https://nightingale.edu/blog/nursesduring-coronavirus/

PAHO. (2021). Caribbean countries boost the capacities of nurses in critical care during COVID-19. https://www.paho.org/en/stories/caribbean-countriesboost-capacities-nurses-critical-care-during-covid-19

Pakhide, M.V., \& Verma, M. (2021). Nursing leadership role in pandemic. Public Health ReviewInternational Journal of Public Health Research, 8(2), 712. doi.org/10.17511/ijphr.2021.i02.01

Raven, J., Wurie, H., \& Witter, S. (2018). Health workers' experiences of coping with the Ebola epidemic in Sierra Leone's health system: A qualitative study. BMC health services research, 18(1), 1-9. https://pubmed.ncbi.nlm.nih.gov/29622025/

Rebmann, T., \& Carrico, R. (2017). Consistent infection prevention: Vital during routine and emerging infectious diseases care. OJIN: The Online Journal of Issues in Nursing, 22(1). doi.org/10.3912/ojin.vol22no01man01

Rosser, E., Westcott, L., Ali, P. A., Bosanquet, J., Castro-Sanchez, E., Dewing, J., ... \& Witham, G. (2020). The need for visible nursing leadership during COVID-19. Journal of Nursing Scholarship. doi.org/10.1111/jnu. 12587 
Rouleau, G., Gagnon, M. P., Côté, J., Payne-Gagnon, J., Hudson, E., \& Dubois, C. A. (2017). Impact of information and communication technologies on nursing care: Results of an overview of systematic reviews. Journal of medical Internet research, 19(4), e122. doi.org/10.1186/s13643-015-0062-y

Sagar, P. L. (2015). Nurses leading the fight against Ebola virus disease. Journal of Transcultural Nursing, 26(3), 322-326.doi.org/10.1177/1043659615574326 Schwartz, J., \& Yen, M. Y. (2017). Toward a collaborative model of pandemic preparedness and response: Taiwan's changing approach to pandemics. Journal of Microbiology, Immunology and Infection, 50(2), 125-132.doi.org/10.1016/j.jmii.2016.08.010

Sampaio, F., Sequeira, C., \& Teixeira, L. (2020). Nurses' mental health during the Covid-19 outbreak: A crosssectional study. Journal of occupational and environmental medicine, 62(10), 783-787. doi.org/10.1097/JOM.0000000000001987

Simonovich, S. D., Spurlark, R. S., Badowski, D., Krawczyk, S., Soco, C., Ponder, T. N., ... \& Tariman, J. D. (2021). Examining effective communication in nursing practice during COVID-19: A large-scale qualitative study. International Nursing Review. doi.org/10.1111/inr.12690

Smith, M. W., Smith, P. W., Kratochvil, C. J., \& Schwedhelm, S. (2017). The psychosocial challenges of caring for patients with Ebola virus disease. Health security, 15(1), 104-109. doi.org/10.1089/hs.2016.0068

Sperling, D. (2021). Ethical dilemmas, perceived risk and motivation among nurses during the COVID-19 pandemic. Nursing ethics, 28(1), 9-22. doi.org/10.1177/0969733020956376

Schwartz, J., \& Yen M. (2017). Toward a collaborative model of pandemic preparedness and response: Taiwan's changing approach to pandemics. Journal of Microbiology Immunology and Infection, 50(2), 125-132.

doi.org/10.1016/j.jmii.2016.08.010
Turale, S., \& Kunaviktikul, W. (2019). The contribution of nurses to health policy and advocacy requires leaders to provide training and mentorship. International nursing review, 66(3), 302304.doi.org/10.1111/inr.12550

USDVA. (2020). For Leaders: Supporting your staff During the Coronarivus (COVID-19) Pandemic. Washington: National Center for PTSD. https://www.ptsd.va.gov/covid/COVID_leaders_sup port_staff.asp

Wilson, A., \& Nguyen, T. N. (2017). The Zika virus epidemic: public health roles for nurses. Online journal of issues in nursing, 22(4). doi.org/10.3912/OJIN.Vol22No01Man04.

WHO. (2021). Global strategic directions for nursing and midwifery 2021-2025.

https://apps.who.int/iris/bitstream/handle/10665/344 562/9789240033863-eng.pdf

WHO. (2020). Quality of care in fragile, conflict-affected and vulnerable settings: Taking action. https://apps.who.int/iris/bitstream/handle/10665/337 842/9789240015203-eng.pdf

Xiong, Y., \& Peng, L. (2020). Focusing on health-care providers' experiences in the COVID-19 crisis. The Lancet Global Health, 8(6), e740-e741. doi.org/10.1016/S2214-109X (20)30214-X

Zhang, X., Huang, D. S., \& Guan, P. (2021). Nursing Scheduling Mode and Experience from the Medical Teams in Aiding Hubei Province During the COVID19 Outbreak: A Systematic Scoping Review of 17 Studies. Risk Management and Healthcare Policy, 14, 1805. doi.org/10.2147/RMHP.S302156 